\title{
Performance Study of an Unconventional Breathresponse PAPR Against a N95 FFR and Conventional PAPRs
}

\author{
Huihui Yang \\ hiyang@mix.wvu.edu
}

Follow this and additional works at: https://researchrepository.wvu.edu/etd

Part of the Industrial Engineering Commons, and the Occupational Health and Industrial Hygiene Commons

\section{Recommended Citation}

Yang, Huihui, "Performance Study of an Unconventional Breathresponse PAPR Against a N95 FFR and Conventional PAPRs" (2019). Graduate Theses, Dissertations, and Problem Reports. 7451.

https://researchrepository.wvu.edu/etd/7451

This Dissertation is protected by copyright and/or related rights. It has been brought to you by the The Research Repository @ WVU with permission from the rights-holder(s). You are free to use this Dissertation in any way that is permitted by the copyright and related rights legislation that applies to your use. For other uses you must obtain permission from the rights-holder(s) directly, unless additional rights are indicated by a Creative Commons license in the record and/ or on the work itself. This Dissertation has been accepted for inclusion in WVU Graduate Theses, Dissertations, and Problem Reports collection by an authorized administrator of The Research Repository @ WVU.

For more information, please contact researchrepository@mail.wvu.edu. 


\title{
Performance Study of an Unconventional Breath- response PAPR Against a N95 FFR and Conventional PAPRs
}

\author{
Huihui Yang
}

\author{
Dissertation submitted \\ to the Benjamin M. Statler College of Engineering and Mineral Resources \\ at West Virginia University \\ in partial fulfillment of the requirements for the degree of \\ Doctor of Philosophy in \\ Industrial Engineering
}

Xinjian He, Ph.D., Chair

Steve Guffey, Ph.D.

Feng Yang, Ph.D.

Anna Allen, M.D.

Ziqing Zhuang, Ph.D.

Department of Industrial and Management Systems Engineering

Morgantown, West Virginia

2019

Keywords: Healthcare Workers, Breath-Response Respirators, PAPR, Protection

Performance, User Preference, Acceptance, Comfort

Copyright 2019 Huihui Yang 


\section{ABSTRACT \\ Performance Study of an Unconventional Breath-response PAPR Against a N95 FFR and Conventional PAPRs Huihui Yang}

Healthcare workers (HCWs) are the first responders when infectious pathogens occur. Powered air-purifying respirators (PAPRs) are one of the most widely used personal protective equipment for healthcare workers. Currently, few studies have been performed with HCWs in the actual healthcare work environments to assess discomforts, acceptance and protective efficiency towards wearing and use of PAPRs. The main purpose of this dissertation was to introduce and assess a brand new unconventional PAPR (Koken breath-response PAPR). The protection performance and user preferance of this unconventional PAPR were studided and compared to that of a N95 FFR and traditional PAPRs.

Firstly, a laboratory experiment was conducted to test the performance of the unconventional breath-response respirator (Koken PAPR) during different breathing flow types and rates, faceseal leakages, and motor conditions (fan on or fan off). The results indicated that this PAPR worked effectively to protect the wearer regardless of the leakage size with the fan on (protection factor, $\mathrm{PF}>52$ ). However, as the flow rate was increased above $115 \mathrm{~L} / \mathrm{min}$ (both constant and cyclic), even with fan on, this PAPR didn't provide enough protection to its user ( $\mathrm{PF}<46$ when there existed leakage).

Then, the second study (Study II) was conducted to evaluate the user perception and acceptance about this unconventional PAPR with compared to a N95 filtering facepiece respirator (FFR). The results showed that subjects preferred the unconventional PAPR over N95 FFR in overall assessment due to less heat and humidity when performing the designed twelve tasks.

Finally, Study III was conducted to evaluate HCWs' comfort, perceived protective efficiency and preference about this unconventional PAPR comparing to three traditional PAPR models in a simulated work environment. The results indicated that this 
unconventional PAPR had the least general comfort, most inspiratory/expiratory effort and overall breathing. 


\section{Acknowledgements}

First and foremost, I would like to express my sincere gratitude to my advisor Dr. Xinjian (Kevin) He. Without his support, I would not have the opportunity to pursue my Ph.D. degree in West Virginia University. My sincerely thanks not only for his tremendous and continuous academic support, but also for his patience, motivation, and immense knowledge. His guidance helped me in all the time of research and writing of this dissertation. Dr. He is the greatest advisor that I have ever met in my Ph.D. study.

I also would like to thank Dr. Anna Allen for providing professional guidance on my dissertation research. This work would not have been possiblely completed without her endless help.

Special thanks go to the rest of my committee members: Dr. Steve Guffey, Dr. Feng Yang and Dr. Ziqing Zhuang for their sincere guidance, valuable suggestions, and insightful comments and encouragement.

My sincere thanks also go to Dan Summers, Adam Hoffman from WVU STEPS lab for being ever so kind to provide me with all the necessary support.

I am grateful to my labmates: Mr. Raphael W. Alwin Dodrill, Mr. Jintuo Zhu, Miss. Lauren MacDowell, and Mrs. Brittany Carver for the excellent cooperation.

I would like to acknowledge that this research was supported by the NIOSH/NPPTL.

I greatly appreciate all the faculty members from the Department of Industrial and Management Systems Engineering for their help and encouragement.

Last but not the least, I would like to thank my parents and my husband for their unceasing encouragement and support throughout my life. 


\section{Table of Contents}

INTRODUCTION ............................................................................. 1

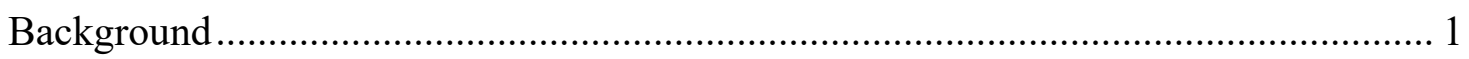

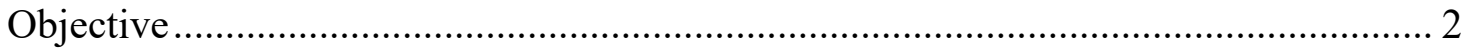

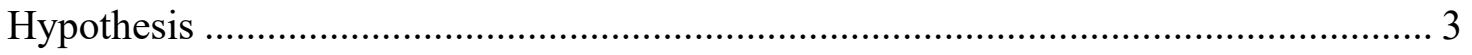

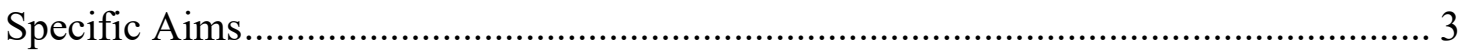

Study I - Lab-based Experimental Study on the Performance of an Unconventional Breath-Response PAPR Respirator .................................. 4

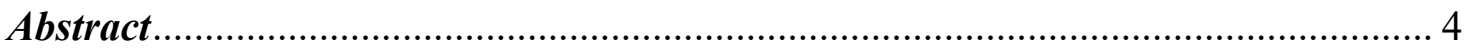

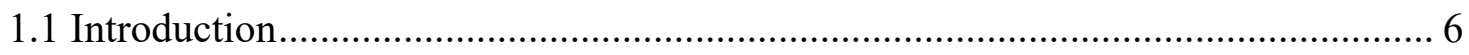

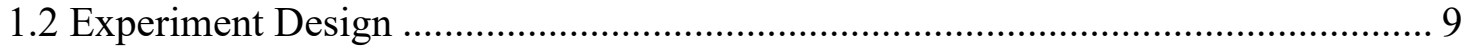

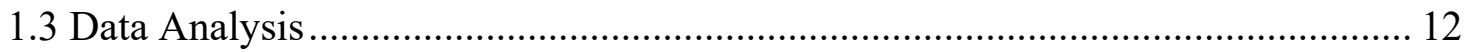

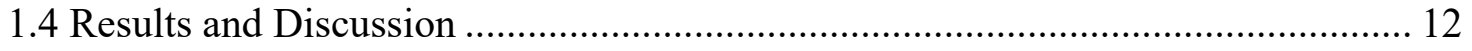

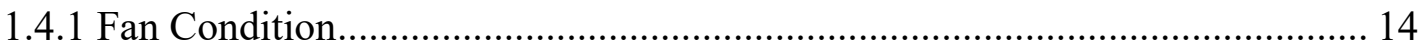

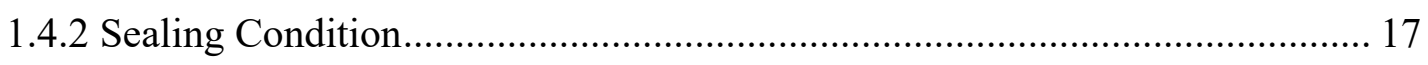

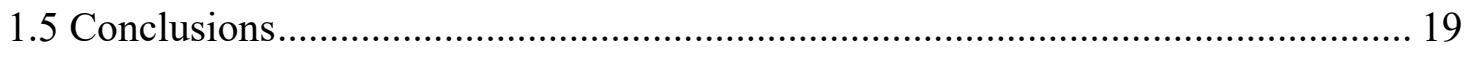

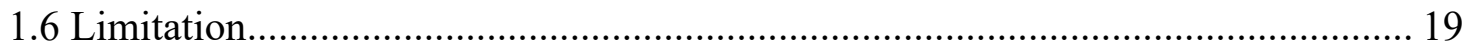

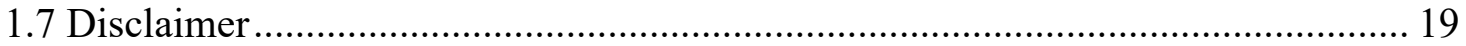

Study II - Assessing user discomfort, acceptance and perceived protective efficiency of an unconventional breath-response PAPR vs. a N95 FFR in selected healthcare work tests (Aim 2) ................................. 21

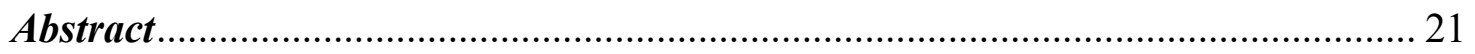

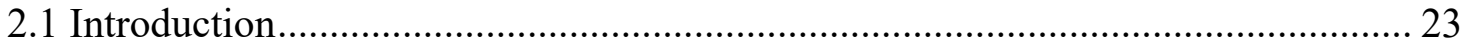

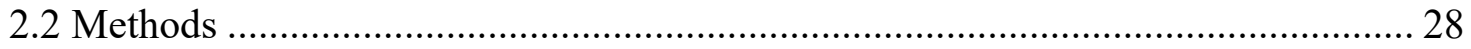

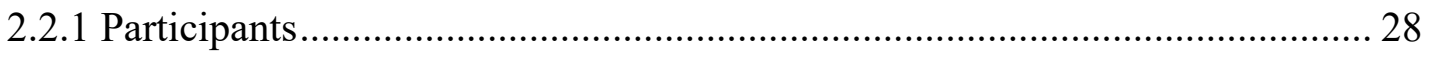

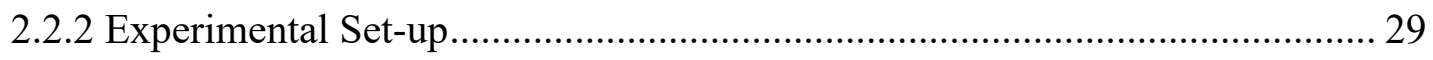

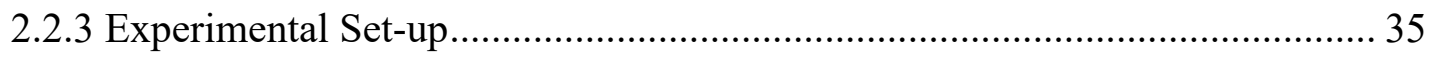

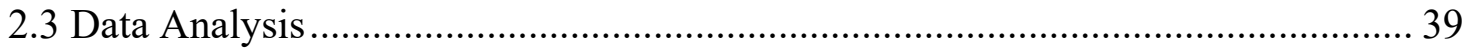

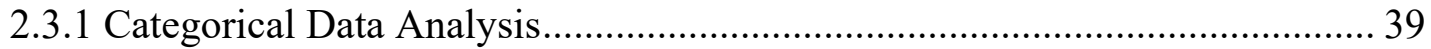

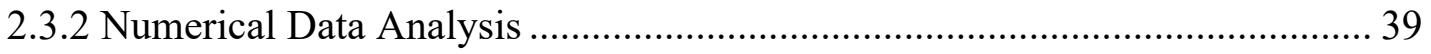

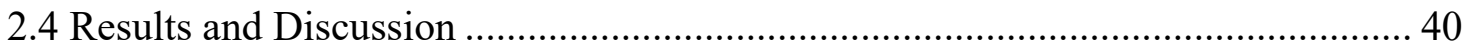


2.4.1 Evaluation on Sixteen Categories ................................................................. 40

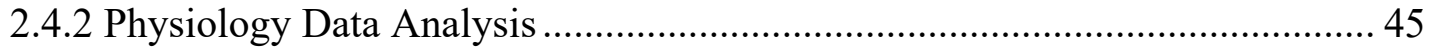

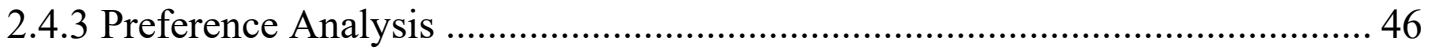

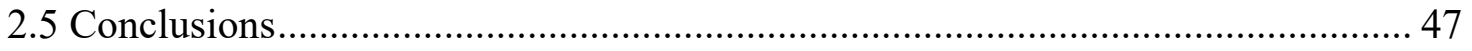

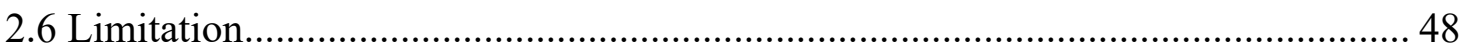

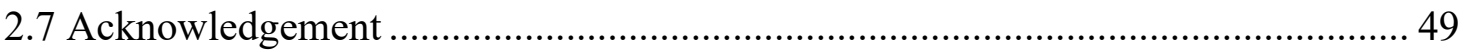

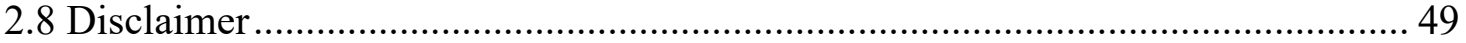

Study III - Assessing user discomfort, acceptance and perceived protective efficiency of an unconventional breath-response PAPR vs. traditional PAPRs in a healthcare work setting (Aim 3) ........................ 50

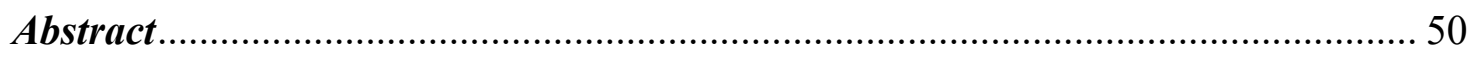

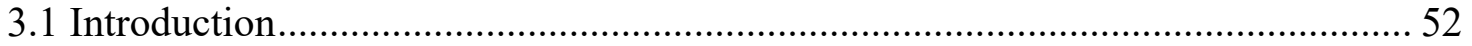

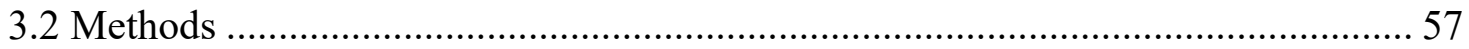

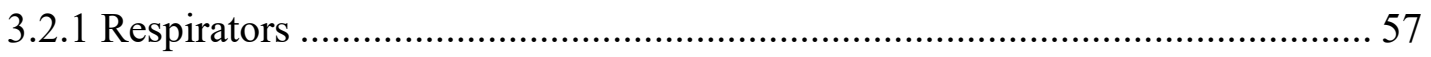

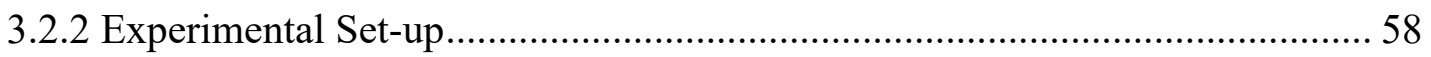

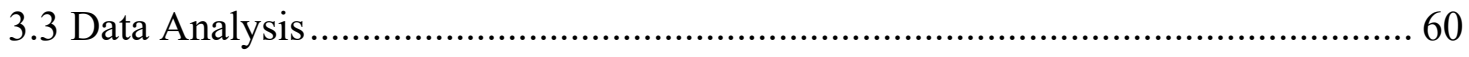

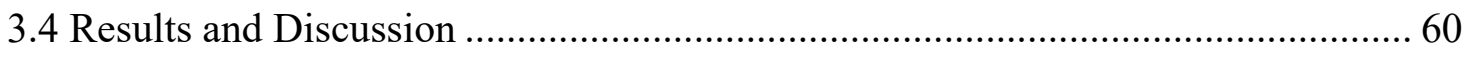

3.4.1 Evaluation on Sixteen Subjective Categories ........................................... 61

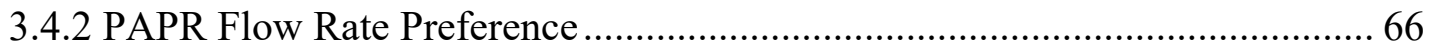

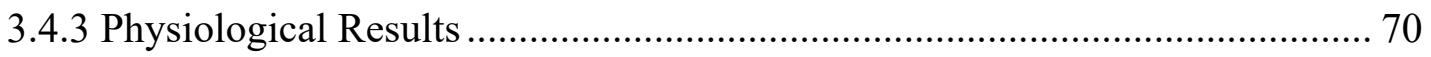

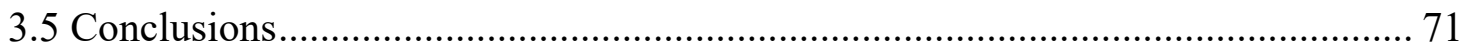

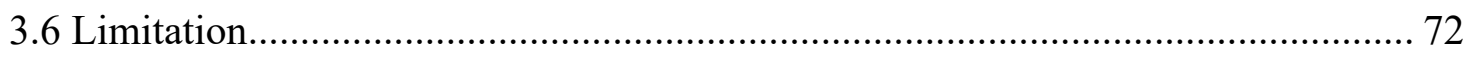

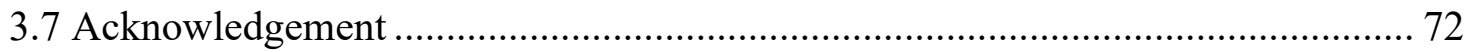

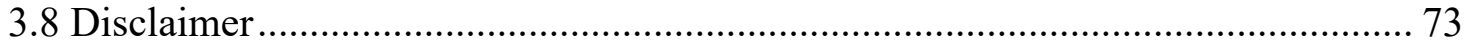

REFERENCES ........................................................................................ 74

Appendix A: Screening Questionnaire ........................................................ 79

Appendix B: Survey Questionnaire ................................................................ 80 


\section{List of Figures}

Figure 1. 1 Experimental Setup (modified from He et al., 2013) ............................... 10

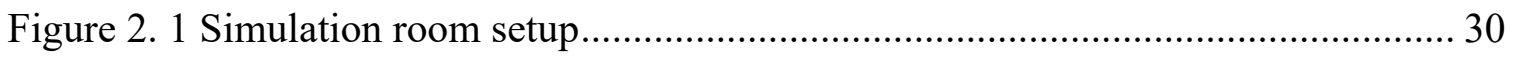

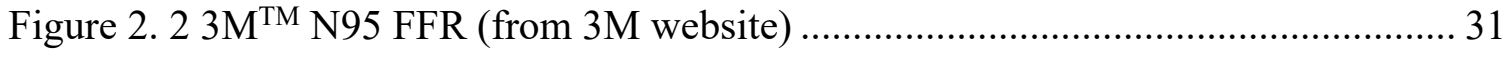

Figure 2. 3 Koken breath-response PAPR .......................................................... 31

Figure 2.4 Vita sign change before and after the test .............................................. 46

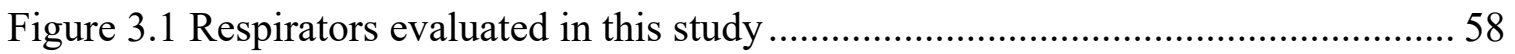

Figure 3.2 Vital Sign Changed Before and After the Test....................................... 70 


\section{List of Tables}

Table 1.1 Summary of experimental variables 11

Table 1.2 Average Penetration Rates of the Unconventional PAPR 13

Table 1.3 Four-way ANOVA results for the total penetration as a function of fan condition, flow type, flow rate and sealing condition. 14

Table 1.4 Three-way ANOVA results for the total penetration as a function of fan condition, flow type, flow rate and sealing condition 15

Table 1.5 Pairwise multiple comparisons: total penetration among four flow rates 15

Table 1.6 Pairwise multiple comparisons: total penetration among four flow rates (ANOVA with Tukey's range test) 15

Table 1.7 Pairwise multiple comparisons: total penetration among four sealing conditions 18

Table 2.1 List and explanation of twelve tasks in the test 31

Table 2.2 Parameters for Evaluation (scales were explained) 35

Table 2.3 Preference evaluation questions. 38

Table 2.4 the Unconventional PAPR Evaluation Statistical Results 41

Table 2.5 N95 FFR Evaluation Statistical Results........................................................ 42

Table 2.6 Global test results when comparing the unconventional PAPR with N95 ...... 44

Table 2.7 Paired t test results of physiological change of HCWs.................................. 46

Table 2.8 Preference, acceptance, and effectiveness about the respirators .................... 47

Table 3.1 Four evaluated PAPRs in the study ....................................................... 57

Table 3.2 Questionnaire survey about user's preference. 60 
Table 3.3 Mean \pm standard deviation values of sixteen categories evaluation of four

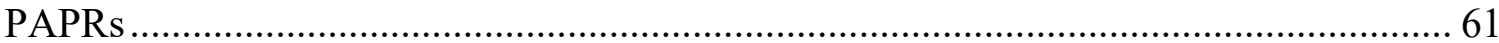

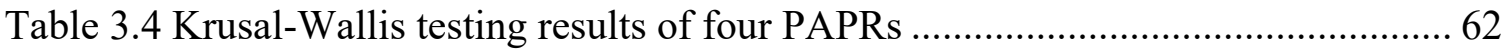

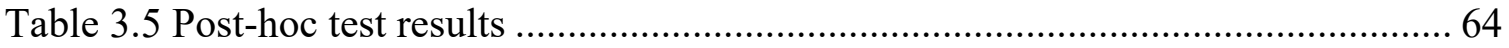

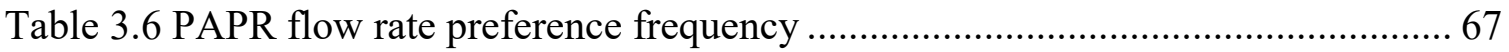

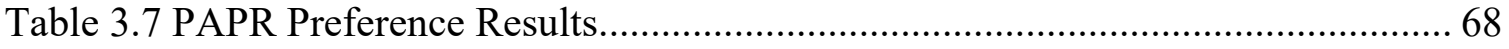

Table 3.8 Paired t test results of physiological change of HCWs................................. 70 


\section{INTRODUCTION}

\section{Background}

Airborne respiratory infectious diseases may present a life-threatening risk for health care workers (HCWs) during pandemic emergencies as well as exposures during routine aerosol-generating procedures. The 2003 severe acute respiratory syndrome (SARS), 2009 Pandemic Influenza A (H1N1) and the Ebola outbreak in 2013-2014 all bring this concern to the immediate forefront. The Centers for Disease Control and Prevention (CDC) recommends that PAPR or N95 FFR be used for workers when coming into airborne disease.

A powered air-purifying respirator is defined as "an air-purifying respirator that uses a blower to force the ambient air through air-purifying elements to the inlet covering” by OSHA 1910.134 Respiratory Protection standard (OSHA 2015). This battery powered blower creates a positive pressure inside the facepiece or hood preventing contaminated air from entering the respirator. PAPRs are divided as half mask PAPRs with assigned protection factor (APF) of 50, full-face piece PAPRs with APF of 1000, helmet and hood PAPRs with APF of 1000 respectively, and loose-fitting face piece PAPRs with APF of 25 (OSHA 2005). The loose-fitting PAPRs do not require fit testing by OSHA (OSHA, 2015). However, PAPRs are usually heavy and expensive. Then the much lighter and relatively inexpensive N95 filtering facepiece respirator (FFR) is also frequently utilized in healthcare work settings to protect against airborne aerosols. 
The breath response powered air-purifying respirator tested in this study is different from traditional PAPRs. It is equipped with Breath Synchronized Air Flow System (BSFS) that supplies an optimum amount of air according to the wearer's breathing pattern and increases energy efficiency of a blower unit. It also focuses on lightweight design and can be utilized in various work settings including tunnel construction work, asbestos removal work and arc welding operation.

Several prior studies have been conducted in the laboratory setting with healthy volunteers to evaluate comfort, tolerance, barriers and user physiological stress of N95 FFRs during exercises or in work settings with HCWs. However, it is not clear if PAPRs are perceived effectively and acceptable to HCWs, and if there are any discomforts that affect the intolerance of use. No previous studies have been performed with HCWs in the actual or simulated healthcare work environments to assess discomforts, acceptance and protective efficiency towards wearing and use of PAPRs. User comfort and tolerance affect their compliance with wearing and therefore the efficiency of protection PAPRs afford. Therefore, it is essential that these NIOSH certified PAPRs particularly the new one from Koken company, can be evaluated by HCWs during their normal work duties and tasks. Worker input about safety devices is an important part of an overall safety program. These results would be useful to respirator manufacturers, standard development organizations, researchers, respiratory protection program managers and end users.

\section{Objective}


This study was designed to evaluate the performance of an unconventional breathresponse powered air-purifying respiratory (PAPR) against a N95 FFR and three traditional PAPRs.

\section{Hypothesis}

The performance of this unconventional PAPR is better than the N95 FFR. User acceptance and perceived protective efficiency is higher when comparing to the three traditional PAPRs and the N95 FFR.

\section{Specific Aims}

Aim 1 (Study I): Assess the performance of an unconventional breath-response PAPR under different breathing flows, faceseal leakages, and fan conditions.

Aim 2 (Study II): Evaluate HCWs' discomfort, acceptance and perceived protective efficiency of the unconventional breath-response PAPR vs. a N95 FFR in selected healthcare work tests.

Aim 3 (Study III): Evaluate HCWs' discomfort, acceptance and perceived protective efficiency of the unconventional breath-response PAPR vs. three traditional PAPRs in a simulated healthcare work setting. 


\section{CHAPTER 1}

\section{Study I - Lab-based Experimental Study on the Performance of an Unconventional Breath-Response PAPR Respirator}

\section{Abstract}

Objectives: This study investigated the effects of breathing flow type and rate, faceseal leakage, and motor condition (fan on or fan off) on the performance of an unconventional breath response PAPR.

Methods: An unconventional PAPR was mounted on a manikin headform exposed to $\mathrm{NaCl}$ aerosol generated by a particle generator in a size of $1.02 \mathrm{~m}^{3}$ chamber. Tests were performed under two flow types, constant flow (inspiratory flow rates $=20,50,85$ and $115 \mathrm{~L} / \mathrm{min}$ ) and cyclic flow (mean inspiratory flow rates $=20,50,85$ and $115 \mathrm{~L} / \mathrm{min}$ ). Four sealing conditions (fully sealed, a $0.8 \mathrm{~mm}$ diameter needle located on one side of the manikin's cheek, two $0.8 \mathrm{~mm}$ diameter needles located both sides of the cheeks, and a $2 \mathrm{~mm}$ diameter needle placed on one side of the manikin's cheek) were taken into consideration to evaluate this unconventional PAPR faceseal leakage. The fan of this PAPR was controlled to be on or off manually and randomly. Total particle concentration inside (Cin) and outside (Cout) the respirator was measured by a particle counter. Then the total penetration of this unconventional PAPR was calculated as $\mathrm{P}=\mathrm{Cin} / \mathrm{Cout}$.

Results: Breathing flow type and rate, faceseal leakage, and motor condition all had significant effects on the performance of this unconventional PAPR. When at low constant or cyclic flow rates $(<85 \mathrm{~L} / \mathrm{min})$, the highest penetration rate was $0.194 \%$. The NIOSH certified half mask PAPR has an OSHA APF of 50, which indicates that this unconventional PAPR worked effectively to protect the wearer regardless of the leakage size with the fan on However, under the flow rate of $115 \mathrm{~L} / \mathrm{min}$ (constant and cyclic), 


\section{CHAPTER 1}

even with fan on, this PAPR didn't provide enough protection to its user. The total penetration was $2.139 \pm 0.140 \%$ at constant flow $115 \mathrm{~L} / \mathrm{min}$ and $3.894 \pm 0.019 \%$ at cyclic MIF of $115 \mathrm{~L} / \mathrm{min}$.

Keywords: Breath response, Healthcare worker, PAPR, unconventional PAPR, total penetration 


\subsection{Introduction}

Powered air-purifying respirator (PAPR) is the respirator using a blower to force contaminated air through a filter to the face mask so the wearer will experience less breathing resistance during inhaling. As all the industries from hospital to chemical plants are actively engaging in upgrading to more advanced processes and exotic materials, it has a substantial increase of the possibility of inhalation hazards. It gets more and more urgent to protect the first responders as well as other workers from air contaminations in the workplace. A broad range of wearers like health care workers, industrial workers or police departments, military personnel choose powered air-purifying respirators (PAPR) as their first respiratory protection in nonimmediately dangerous life health (IDLH) environments (Robbins, 2002, Freund, 2013). PAPRs provide more protection than conventional and non-powered respirators do (Robbins, 2002). They are mainly applied when people need to wear respirators in a long time and require more comfort since PAPRs can draw cooling purified air into the facepiece in warm environment.

The assigned protection factor (APF) of half mask PAPRs is 50 set by Occupational Safety \& Health Administration (OSHA), and for full mask PAPRs it is 1000 (OSHA, 2009). Lenhart et al. conducted a study on a half mask PAPR in an actual lead smelter. They reported that the geometric mean of the workplace protection factor (WPF) of that half mask PAPR was 431 (Lenhart et al., 1984). Simulated WPF studies on half mask PAPR were also measured by light-scattering photometer which were agree with the APF (DaRoza et al., 1984). However, Myers et al, 1984 reported that APFs were not able to be accurately applied in the actual workplace. They found that the two tested PAPRs had a lower workplace protection factor (WPF) less than the APF of 1,000. The result of Myer et al. research in a silica bagging 
operation indicated that the actual field performance of PAPR (WPF was from 16 to 215) was much lower than the APF (Myers et al., 1983). There was no obvious relationship between assigned protection factors and workplace protection factors. Some following studies were conducted on WPF and the simulated workplace protection factor (SWPF) as well (Gaboury et al, 1993).

Ergonomics is another important consideration for using the PAPRs. NIOSH suggested health care workers to use PAPR instead of disposable respirators when exposed to tuberculosis (Leidel at al., 1992). Doctors had concerns that PAPRs (loose-fitting) would appear frightening to their patients as well as impede the communication with patient due to the noise produced by the fan inside the respirator (Nelson et al., 1992). Only a total of $10 \%$ out of 67 respondents found that hearing was impaired by using the PAPR during severe acute respiratory syndrome (SARS) outbreak and two-thirds were agreed or strongly agreed that they looked frightening to patients (Khoo et al., 2005). However, very limited amount of respondents felt uncomfortable and $84 \%$ of respondents preferred to use PAPR in highly contagious diseases cases (Khoo et al., 2005). Schumacher et al. also found that PAPR didn't appear to reduce any flexibility or delay any treatment during a simulated treatment of chemical, biological, radiological or nuclear $(\mathrm{CBRN})$ patients inside an ambulance but improved the ease of breathing (Schumacher et al., 2008). While reducing the blower air flow rates, the comfort and cooling effects of PAPR would be decreased (Johnson et al., 2005).

Compared to the conventional PAPRs mentioned above, the unconventional Koken breath-response PAPR (Model BL-100U, Koken Ltd., Tokyo, Japan) used in this study has a small circuit called breath-synchronized air flow system (BSFS) which can keep pressure inside the respirator be constant during inhalation and exhalation by controlling the fan speed (Koken 
Ltd., product website; Koken Ltd., Breath-Response PAPR website). Therefore, enable longer filter life than constant flow PAPRs.

Unlike conventional constant-flow PAPR, this breath-response PAPR supplies airflow according to the wearer's breathing pattern. When the wearer's breathing flow increases, this breath-response PAPR will supply more airflow to keep a slightly positive pressure inside the mask with "added protection" mentioned in introduction of the Koken breath-response PAPR (Koken Ltd., Breath-Response PAPR website). When the wearer breathes gently, it provides less volume of airflow, therefore the life of the filter and the battery will be signifantly extended. Theoretically, there is no air supplied into the respirator during exhalation. Thus, energy is saved as well as breathing loading is reduced. As long as sufficient airflow is ensured, the pressure inside the respirator stays positive, then inward leakage would be avoided, and high protection is obtained.

To address the problem of the humidity inside the facepeice caused by exhalation when working in warm environment, this breath-response PAPR works the same as the conventional PAPRs that blowcool air into the respirator through the motor fan. However, contrasted to the conventional PAPRs which are always heavy, bulk, sometimes even interfere withwearer's activity, BL- series Koken PAPRs (Model BL-100U, Koken Ltd., Tokyo, Japan) weight only 372g including mask body, filter, and battery kits, which can significantly reduced the physiological burden that the conventional PAPRs such as 3M Versaflo TR-300 placing on the wearer. Wearers would feel more comfortable and less restricted when performing their daily tasks. It is to be noted that this is a new type of PAPR currenlyt available in the Japanese market (not in the US market) and has not been certified by NIOSH. 
The objective of this study was to evaluate the manikin-based performance of the unconventional Koken PAPR (Model BL-100U, Koken Ltd., Tokyo, Japan, with filter BRD-8U of efficiency $99.95 \%$ which is similar to P100 filter) on different breathing flow types and rates, faceseal leakages, and motor conditions (fan on or fan off) through the overall (non-sizeselective) penetration of $\mathrm{NaCl}$ particles into the PAPR.

\subsection{Experiment Design}

The tested PAPR (Model BL-100U, Koken Ltd., Tokyo, Japan) was donned on a manikin headform which placed in a chamber $(1.02 \mathrm{~m} \times 1.02 \mathrm{~m} \times 1.02 \mathrm{~m})$. The experimental setup was shown in Figure 1.1. NaCl aerosols were generated by a particle generator (model 8026, TSI Inc., Shoreview, MN, USA).

Tests were conducted in two different breathing flow types: constant and cyclic. Constant flow was created by the bench vacuum which is set in West Virginia University combined with a vacuum pump (Model VP 2200, HFS, Los Angeles, California, USA) because for some reasons bench vacuum and vacuum pump cannot reach the desired flow rate individually. And cyclic flows were simulated by a breathing simulating machine (serial 1101, Hans Rudolph, Inc., Shawnee, KS, USA) with a HEPA filter to prevent the $\mathrm{NaCl}$ aerosols re-entering to the respirator during exhalation. 

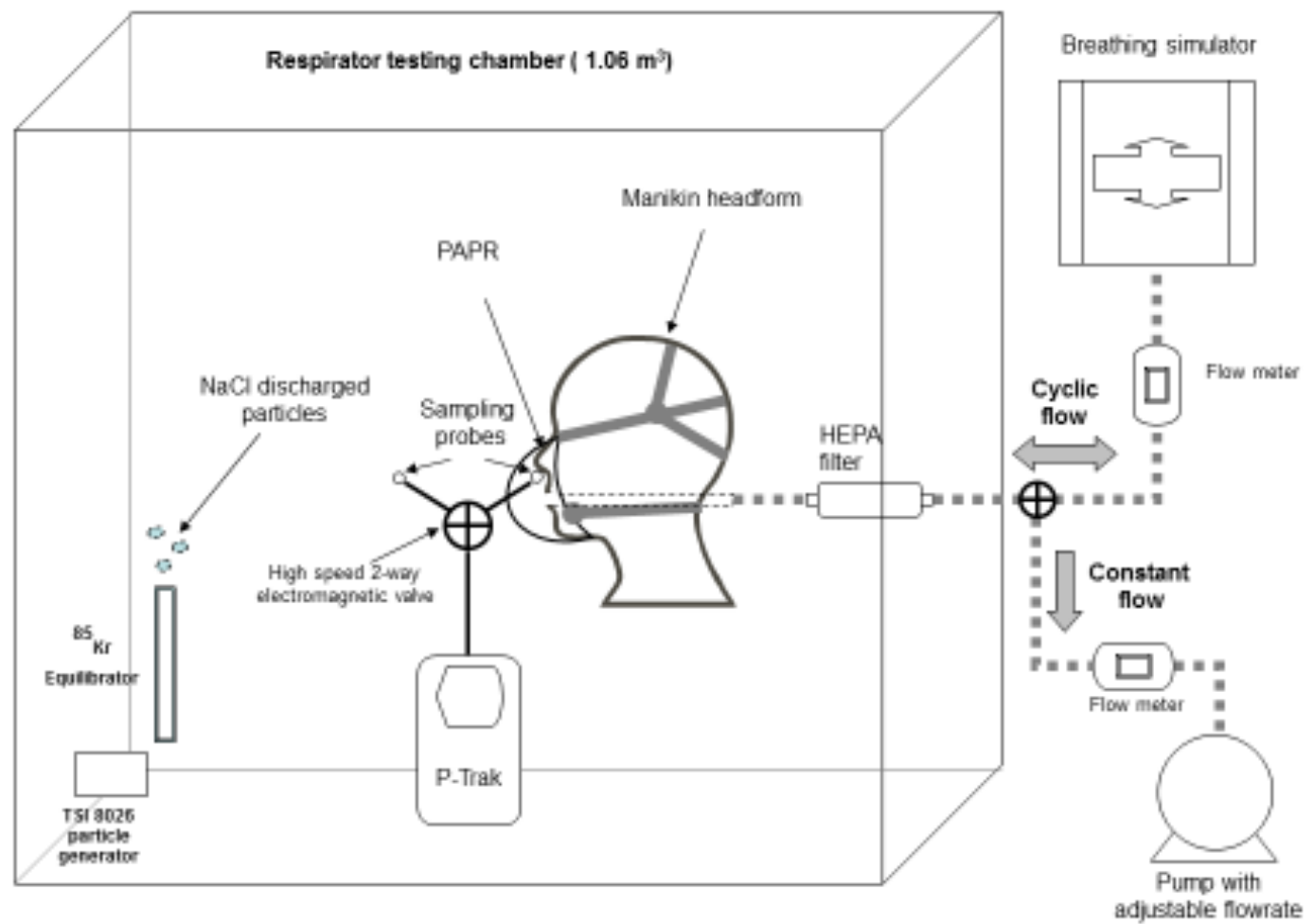

Figure 1. 1 Experimental Setup (modified from He et al., 2013)

Four different flow rates were adopted in constant flow and cyclic flow $(20,50,85$, and $115 \mathrm{~L} / \mathrm{min}$ for constant flow, and mean inspiratory flows (MIF) of 20, 50, 85, and $115 \mathrm{~L} / \mathrm{min}$ were selected for cyclic flow). These airflows are set up to simulate worker's breathing on light, moderate, or high workloads, respectively. The reason why $115 \mathrm{~L} / \mathrm{min}$ was chosen as a test flow rate is that constant airflow of $115 \mathrm{~L} / \mathrm{min}$ is used in the NIOSH certification standard for tightfitting PAPR tests (OSHA, 2006).

To evaluate the effects of faceseal leakage on this unconventional PAPR penetration, four leakage conditions were considered in this study (fully sealed, a $0.8 \mathrm{~mm}$ diameter needle located on one side of the manikin's cheek, two $0.8 \mathrm{~mm}$ diameter needles located both sides of the cheeks, and a $2 \mathrm{~mm}$ diameter needle which also was placed on one side of the 
cheek). Acrylic latex caulk was applied to seal the respirator on the manikin. Once the respirator was placed in its sealing condition, it would not be changed until that test had been completed.

The fan of the PAPR was controlled by a switch which can be adjusted by the wearer. If the fan inside the respirator is off, then the PAPR works just like a standard elastomeric halfmask respirator. Three replicates were designed at each test condition combination. Fan condition and breathing airflow rate were also randomized in the whole experiment. Thus, there were 192 measurements in total shown in Table 1.1.

Table 1.1 Summary of experimental variables

\begin{tabular}{l|l}
\hline Variable & Levels \\
\hline Fan condition & 2 (fan on, fan off) \\
\hline Sealing condition & $\begin{array}{l}4 \text { (fully sealed, one } 0.8 \mathrm{~mm} \text { leakage, two } 0.8 \mathrm{~mm} \text { leakage, one } \\
2 \mathrm{~mm} \text { leakage) }\end{array}$ \\
\hline Flow type & 2 (constant, cyclic) \\
\hline Flow rate & $4(20,50,85,115 \mathrm{~L} / \mathrm{min}$ for both constant and cyclic) \\
\hline Replicates & 3 \\
\hline Total runs & $2 * 4 * 2 * 4 * 3=192$ \\
\hline
\end{tabular}

Particle concentrations (non-size-selective) outside (Cout) and inside (Cin) the respirator were measured by a particle counter (P-track, model 8525, TSI Inc., Shoreview, MN, USA) with particle size range from $20 \mathrm{~nm}$ to $1000 \mathrm{~nm}$. Each measurement lasted one minute, and 60 data points were recorded. The particle penetration is calculated as the proportion of inside and outside concentrations:

$$
P=\frac{C_{\text {in }}}{C_{\text {out }}} \times 100 \%
$$




\subsection{Data Analysis}

Data collected from P-trak were exported to spreadsheets. Statistical analysis was performed by using R studio. Average penetration rate and standard deviation for each experimental variable combination were calculated. Analysis of variance (four-way ANOVA) were analyzed to evaluate the effects of fan condition, sealing condition and breathing flow type and rate on particle penetration. The three-way ANOVA with Turkey honest significant difference (HSD) tests were performed to exam the effects of sealing condition, flow type and rate while the fan is on. P-value of $<0.05$ was considered significant.

\subsection{Results and Discussion}

As shown in Table 1.2, when fan was turned on, the total penetration was very low $(<0.02 \%)$ at both constant and cyclic flow rate of 20,50 , and $85 \mathrm{~L} / \mathrm{min}$ in any leakage condition except when at cyclic MIF of $85 \mathrm{~L} / \mathrm{min}$ with $2 \mathrm{~mm}$ diameter needle leakage, the overall penetration was $0.194 \pm 0.045 \%$. Statistical analysis (p-value $<0.001$ ) revealed that motor condition significantly affected the performance of this unconventional PAPR. As the flow rate increased from 20 to $115 \mathrm{~L} / \mathrm{min}$, the overall penetration range was from zero to $3.894 \pm 0.019 \%$ when the fan was on. Under constant flow of $115 \mathrm{~L} / \mathrm{min}$ in any leakage conditions except $2 \mathrm{~mm}$ diameter needle leakage, the penetrations $\mathrm{P}_{\text {constant }}$ were approximately 5 to 10 times larger than those in cyclic MIF of $115 \mathrm{~L} / \mathrm{min} \mathrm{P}_{\text {cyclic. The possbile reason for this difference is that particles }}$ continuously penetrate into the respirator during constant flow, whereas in cyclic flow, exhalation is a particle-free process because particles are diluted during the returning flow. Therefore, it is reasonable that constant flow penetration rate is greater than the cyclic flow. 
However, only constant flow of $115 \mathrm{~L} / \mathrm{min}$ and cyclic MIF of $115 \mathrm{~L} / \mathrm{min}$ were statistically significantly different.

Table 1.2 Average Penetration Rates of the Unconventional PAPR

\begin{tabular}{|c|c|c|c|c|c|}
\hline \multirow[b]{2}{*}{$\begin{array}{c}\text { Motor } \\
\text { Condition }\end{array}$} & \multirow[b]{2}{*}{$\begin{array}{c}\text { Flow Type } \\
\text { and Flow Rate } \\
\text { (L/min) }\end{array}$} & \multicolumn{4}{|c|}{ Penetration, \% (Mean \pm SD) } \\
\hline & & $\begin{array}{l}\text { Fully } \\
\text { Sealed }\end{array}$ & $\begin{array}{l}\text { One } 0.8 \mathrm{~mm} \\
\text { Needle }\end{array}$ & $\begin{array}{c}\text { Two 0.8mm } \\
\text { Needles }\end{array}$ & $\begin{array}{l}\text { One } 2 \mathrm{~mm} \\
\text { Needle }\end{array}$ \\
\hline \multirow[t]{8}{*}{ Fan on } & Constant, 20 & $0.002 \pm 0.000$ & $0.000 \pm 0.000$ & $0.000 \pm 0.000$ & $0.001 \pm 0.000$ \\
\hline & Constant, 50 & $0.001 \pm 0.000$ & $0.000 \pm 0.000$ & $0.000 \pm 0.000$ & $0.001 \pm 0.000$ \\
\hline & Constant, 85 & $0.001 \pm 0.000$ & $0.001 \pm 0.000$ & $0.001 \pm 0.000$ & $0.001 \pm 0.000$ \\
\hline & Constant, 115 & $0.485 \pm 0.040$ & $2.139 \pm 0.140$ & $1.923 \pm 0.165$ & $1.913 \pm 0.201$ \\
\hline & Cyclic, 20 & $0.000 \pm 0.000$ & $0.000 \pm 0.000$ & $0.000 \pm 0.000$ & $0.001 \pm 0.000$ \\
\hline & Cyclic, 50 & $0.000 \pm 0.000$ & $0.000 \pm 0.000$ & $0.000 \pm 0.000$ & $0.001 \pm 0.000$ \\
\hline & Cyclic, 85 & $0.000 \pm 0.000$ & $0.010 \pm 0.001$ & $0.024 \pm 0.008$ & $0.194 \pm 0.045$ \\
\hline & Cyclic, 115 & $0.000 \pm 0.000$ & $0.217 \pm 0.010$ & $0.465 \pm 0.016$ & $3.894 \pm 0.019$ \\
\hline \multirow[t]{8}{*}{ Fan off } & Constant, 20 & $0.001 \pm 0.000$ & $1.638 \pm 0.048$ & $3.800 \pm 0.247$ & $33.259 \pm 1.031$ \\
\hline & Constant, 50 & $0.001 \pm 0.000$ & $1.292 \pm 0.013$ & $3.111 \pm 0.064$ & $27.233 \pm 1.118$ \\
\hline & Constant, 85 & $0.001 \pm 0.000$ & $1.119 \pm 0.014$ & $2.552 \pm 0.038$ & $22.492 \pm 0.558$ \\
\hline & Constant, 115 & $0.000 \pm 0.000$ & $7.180 \pm 0.142$ & $10.435 \pm 0.505$ & $20.758 \pm 1.185$ \\
\hline & Cyclic, 20 & $0.061 \pm 0.008$ & $1.532 \pm 0.032$ & $3.579 \pm 0.197$ & $25.705 \pm 0.944$ \\
\hline & Cyclic, 50 & $0.030 \pm 0.000$ & $0.604 \pm 0.020$ & $1.407 \pm 0.029$ & $11.894 \pm 1.231$ \\
\hline & Cyclic, 85 & $0.030 \pm 0.003$ & $0.586 \pm 0.005$ & $1.315 \pm 0.028$ & $10.614 \pm 0.205$ \\
\hline & Cyclic, 115 & $0.040 \pm 0.001$ & $0.567 \pm 0.015$ & $1.267 \pm 0.023$ & $9.769 \pm 0.324$ \\
\hline
\end{tabular}

For $2 \mathrm{~mm}$ diameter needle leakage, the overall penetration with constant flow of $115 \mathrm{~L} / \mathrm{min}$ was $1.913 \pm 0.201 \%$, which was nearly two-fold lower than the one achieved in cyclic flow $(3.894 \pm 0.019 \%)$. Interactions between leakages and flow rate can be an explanation for this. Compared to the fan off condition, for flow rate changed from 20 to $115 \mathrm{~L} / \mathrm{min}$ regardless of flow type, the performance of this unconventional PAPR was much better in fan on condition. When there's no leakage, the penetration rates were less than $0.5 \%$. However, noticeably, the experimental results showed that this unconventional PAPR didn't work very well at high flow rate or heavy workload even with the motor on when leakages existed. The highest penetration 
$(3.89 \pm 0.019 \%)$ happened at leakage size of $2 \mathrm{~mm}$ diameter needle inserted at cyclic flow rate of $115 \mathrm{~L} / \mathrm{min}$.

A four-way ANOVA (see Table 1.3) shows that the fan condition and sealing condition significantly affected the total penetration of the Koken PAPR ( $<0.001)$. Flow type didn't show a significant effect on the overall penetration rate $(\mathrm{P}>0.05$, see Table 1.3) regardless of fan condition, flow rate, and sealing condition, which is consistent with research of He, et al., (2013).

Table 1.3 Four-way ANOVA results for the total penetration as a function of fan condition, flow type, flow rate and sealing condition

\begin{tabular}{llllll}
\hline Source & DF & Sum of Square & Mean Square & F value & P value \\
\hline fan condition & 1 & 579.6 & 579.6 & 21.252 & $<0.0001$ \\
flow type & 1 & 71.3 & 71.3 & 2.613 & 0.112 \\
flow rate & 3 & 3.3 & 3.3 & 0.121 & 0.729 \\
sealing condition & 3 & 1108.7 & 369.6 & 13.551 & $<0.0001$ \\
\hline
\end{tabular}

\subsubsection{Fan Condition}

\section{a. Fan on condition}

When controlling fan as on a condition, a three-way ANOVA was analyzed in R studio shown in Table 1.4. When the fan was turned on, flow rate had a significant impact on the total penetration of the respirator. The pairwise comparison results for four flow rates $(20,50,85$ and $115 \mathrm{l} / \mathrm{min}$ ) were presented in Table 1.5 and 1.6. The total penetrations obtained at both constant $(1.615 \%)$ and cyclic $(1.144 \%)$ flow rate of $115 \mathrm{~L} / \mathrm{min}$ were significantly $(\mathrm{P}<0.05)$ higher than those flow rates of 20,50 , and $85 \mathrm{~L} / \mathrm{min}$. Sealing conditions didn't significantly impact the total penetration. Because when the fan was turned on, the pressure inside the respirator maintained positive that air movement would be outward. 
Table 1.4 Three-way ANOVA results for the total penetration as a function of fan condition, flow type, flow rate and sealing condition

\begin{tabular}{llllll}
\hline Source & DF & $\begin{array}{l}\text { Sum of } \\
\text { Square }\end{array}$ & $\begin{array}{l}\text { Mean } \\
\text { Square }\end{array}$ & F value & P value \\
\hline flow type & 1 & 0.086 & 0.086 & 0.152 & 0.69977 \\
flow rate & 3 & 6.8 & 6.8 & 11.963 & 0.00188 \\
sealing condition & 3 & 1.994 & 0.665 & 1.17 & 0.3403 \\
\hline
\end{tabular}

Table 1.5 Pairwise multiple comparisons: total penetration among four flow rates

\begin{tabular}{ccc}
\hline $\begin{array}{c}\text { Tukey } \\
\text { Grouping }\end{array}$ & $\begin{array}{c}\text { Mean } \\
\text { Penetration } \\
(\%)^{2}\end{array}$ & $\begin{array}{c}\text { flow type and } \\
\text { rates (L/min) }\end{array}$ \\
\hline $\mathrm{A}$ & 0.001 & constant, 20 \\
$\mathrm{A}$ & 0.001 & constant, 50 \\
$\mathrm{A}$ & 0.001 & constant, 85 \\
$\mathrm{B}$ & 1.615 & constant, 115 \\
\hline
\end{tabular}

${ }^{1}$ Means that flow type \& rates are not significant if they have the same letter.

${ }^{2}$ the penetration was calculated over sealing conditions when fan was on.

Table 1.6 Pairwise multiple comparisons: total penetration among four flow rates (ANOVA with Tukey's range test)

\begin{tabular}{ccc}
\hline $\begin{array}{c}\text { Tukey } \\
\text { Grouping }\end{array}$ & $\begin{array}{c}\text { Mean } \\
\text { Penetration } \\
(\%)^{2}\end{array}$ & $\begin{array}{c}\text { flow type and } \\
\text { rates (L/min) }\end{array}$ \\
\hline $\mathrm{A}$ & 0 & cyclic, 20 \\
$\mathrm{A}$ & 0 & cyclic, 50 \\
$\mathrm{A}$ & 0.057 & cyclic, 85 \\
$\mathrm{B}$ & 1.144 & cyclic, 115 \\
\hline
\end{tabular}

${ }^{1}$ Means that flow type \& rates are not significant if they have the same letter.

${ }^{2}$ the penetration was calculated over sealing conditions when fan was on.

\section{b. Fan off condition}

When the fan is off, this unconventional PAPR just works as a half-mask elastomeric respirator with high efficiency (99.95\%) filter. From table 1.2, it shows that the overall penetration was less than $0.03 \%$ at flow rate of $85 \mathrm{~L} / \mathrm{min}$ when the respirator was fully sealed. Since this unconventional PAPR was equipped with a high efficiency filter, particles mainly entered the respirator through faceseal leakage instead of the filter media. It was also validated 
by the significant difference penetration between fully sealed conditions and partially sealed conditions. The lowest penetration obtained from partial sealing was at least 1000 greater than that in fully sealed condition. Therefore, the total particle penetration includes two parts: penetration from faceseal leakage $\left(\mathrm{P}_{\mathrm{L}}\right)$ with air flow $\left(\mathrm{Q}_{\mathrm{L}}\right)$ and penetration from filter $\left(\mathrm{P}_{\mathrm{F}}\right)$ with flow $\left(\mathrm{Q}_{\mathrm{F}}\right)$. According to the previous study He et al., 2013, the overall penetration can be written as:

$$
P=\frac{C_{\text {in }}}{C_{\text {out }}}=P_{F} \frac{Q_{F}}{Q}+P_{L} \frac{Q_{L}}{Q} \approx \frac{Q_{L}}{Q}
$$

Where $\mathrm{Q}$ is the breathing flow.

When a leakage was present, increasing the MIF of cyclic flow from 20 to $115 \mathrm{~L} / \mathrm{min}$, the overall penetration decreased in corresponding sealing conditions. Same thing happened when constant flow rate increased from 20 to $85 \mathrm{~L} / \mathrm{min}$ but then penetration increased as flow rate went up from 85 to $115 \mathrm{~L} / \mathrm{min}$. As described in Eq.2, since filter penetration has little contribution on the total penetration, as the breathing flow Q increases, it is highly possible that the velocity of aerosol particle increases, the ratio of $\mathrm{Q}_{\mathrm{L}}$ to $\mathrm{Q}$ declined, thus total penetration declined. In fact, the relationship between $\mathrm{Q}_{\mathrm{L}}$ and total flow Q (Q $\left.\mathrm{Q} / \mathrm{Q}\right)$ was discussed previously in He et al., 2013 study. They did an individual experiment on half-mask elastomeric respirator with constant breathing flow. It indicated that the proportion of $\mathrm{Q}_{\mathrm{L}} / \mathrm{Q}$ declined as increasing flow rate due to high negative pressure inside the respirator generated high flow resistance, which consequentlyreduced the value of $\mathrm{Q}_{\mathrm{L}} / \mathrm{Q}$, namely penetration. Notably, this relation can also be applied to cyclic flow as stated in their study. The similar results were also found in other research. In Cho et al., 2010 study, when the diameter of aerosol particles was greater than 500nm, with the increasing of flow rate, particle penetration decreased. And in He et al., 2013 
experiment, the unsealed half-mask respirator with $\mathrm{P}-100$ filter penetration declined by increasing flow rate under plastic challenge aerosol with particle size of $>100 \mathrm{~nm}$.

Similar to the fan on condition, $\mathrm{P}_{\text {cyclic }}$ value was about 2 to 10 times lower than $\mathrm{P}_{\text {constant }}$ obtained in constant flow if leakage was set. Nevertheless, when the PAPR was fully sealed, $\mathrm{P}_{\text {cyclic }}$ values were rather lower than $\mathrm{P}_{\text {constant }}$ values, but they were still very low. The highest one was $0.061 \pm 0.008 \%$.

\subsubsection{Sealing Condition}

\section{a. Fully sealed condition}

When the fan was on, penetration increased with flow rate, and the penetration at constant flow of $115 \mathrm{~L} / \mathrm{min}$ was $0.485 \pm 0.040 \%$, which was apparently greater than any one at other constant flows even cyclic flows. Considering a single unit area of the filter, assuming that resistance force is constant, the drug force $\mathrm{F}_{\mathrm{D}}$ making the aerosol pass through the filter, according to Aerosol Technology: Properties, Behavior, and Measurement of Airborne Particles by By William C. Hinds, is:

$$
F_{D}=K \rho_{g} \frac{\pi}{4} d^{2} V^{2}
$$

Where:

$\mathrm{K}$ is a constant of proportionality

$\rho_{g}$ is the density of the aerosol penetrating the filter

$\mathrm{D}$ is the diameter of the aerosol penetrating the filter

$\mathrm{V}$ is the velocity of the aerosol penetrating the filter 
As we can see, if we increase the velocity the particle, in our experiment, the flow rate, the drag force will be increased. It means that more particles go into the filter, then penetration turn to be larger.

Interestingly, the penetration was approaching zero when the fan was off at constant flow of $115 \mathrm{~L} / \mathrm{min}$, which was significantly different from the one when the fan was on at the same flow rate. It seems that the fan has a reverse effect on penetration under constant flow. One possible explanation is that when the fan was on, it blew additional air into the respirator besides the air created by the pump, which caused more air flow than in fan off condition. As a result, the penetration was higher.

Another finding was that the overall penetration in cyclic was even greater than in constant flow though they were both very low.

\section{b. Partial sealing condition}

As shown in table 1.2, when fan was on, at most cases, penetration increased as flow rates increased. It was clear that sealing conditions had significant impacts $(<0.0001)$ on respirator penetration rate (see Table 1.3). The pairwise multiple comparisons confirmed that the leakage with a diameter of $2 \mathrm{~mm}$ needle produced the highest mean penetration value $(10.483 \%)$.

Table 1.7 Pairwise multiple comparisons: total penetration among four sealing conditions

\begin{tabular}{ccl}
\hline $\begin{array}{c}\text { Turkey } \\
\text { group }^{1}\end{array}$ & $\begin{array}{c}\text { Mean } \\
\text { Penetration }^{2}(\%)\end{array}$ & \multicolumn{1}{c}{ Sealing Condition } \\
\hline A & 0.041 & Fully Sealed \\
A & 1.055 & $\begin{array}{l}\text { a diameter of } 0.08 \mathrm{~mm} \text { needle leakage } \\
\text { Two diameter of } 0.08 \mathrm{~mm} \text { needles } \\
\text { A }\end{array}$ \\
leakage
\end{tabular}

${ }^{1}$ Means that sealing conditions are not significant if they have the same letter. 
${ }^{2}$ the penetration was calculated over flow rates under constant flow type when fan was on.

\subsection{Conclusions}

An overall performance of a Koken PAPR (unconventional breath-reponse type) was evaluated with respect to breathing flow type and rate, faceseal leakage, and motor condition. All these factors had a significant effect on the performance of this unconventional PAPR. The highest penetration rate was $0.194 \%$ when the breathing flow rate was under $85 \mathrm{~L} / \mathrm{min}$. Increasing flow rate increased penetration when fan worked properly. And with leakage size increased, total penetration increased except under constant flow of $115 \mathrm{~L} / \mathrm{min}$. A significant difference in penetration was found in different motor conditions (fan on and off). The total penetration was significantly lower in fan on condition than in fan off condition. Results indicate that this unconventional PAPR works effectively under light or moderate work loading, but it is not recommended to use under heavy working loading.

\subsection{Limitation}

A major limitation of this study was that a manikin was used which might not represent actual movement of human being. Future studies are needed to evaluate the performance of this unconventional PAPR using human subjects.

\subsection{Disclaimer}

The findings and conclusions of this article are those of the authors and do not necessarily represent the views of the National Institute for Occupational Health and Safety. 
Mention of a commercial product or trade name does not constitute endorsement by the National Institute for Occupational Safety and Health. 


\title{
CHAPTER 2
}

\section{Study II - Assessing user discomfort, acceptance and}

\author{
perceived protective efficiency of an unconventional breath-
}

\author{
response PAPR vs. a N95 FFR in selected healthcare work
}

\section{tests (Aim 2)}

\section{Abstract}

Objective: To evaluate user's discomfort, acceptance and perceived protective efficiency of an unconventional PAPR comparing with a N95 FFR in a simulated work setting.

Methods: Thirty-three healthcare workers (HCWs) were recruited to participate this study. Subjects were asked to perform twelve designated tasks in a simulated healthcare work environment at West Virginia Simulation Training and Education for Patient Safety lab by wearing those two respirators for 30 minutes. After finishing the tasks, they were asked to give some subjective evaluations about the tested unconventional PAPR and N95 FFR by using a survey (see Appendix B). The survey included sixteen subjective categories about how HCWs perceived this respirator as well as some preference questions. Physiological variables (heart rate, respiratory rate and blood oxygen level) were measured.

Results: The results showed that subjects preferred the unconventional PAPR over N95 FFR in overall assessment due to less heat and humidity when performing the designed twelve tasks wearing respirators. facial and body heat and overall thermal was reported as the one of the main reasons for the noncompliance of N95. However, when asked if the tested respirators interfered their duties in the study, the unconventional breath-response PAPR was reported to have more interferences with their work and also was difficult to put on and operate than N95. Regardless of low-risk or high-risk task would be taken, there was no preference on these two respirators and most subjects thought that both of they can work effectively. However, more than $80 \%$ subjects thought N95 was more 


\section{CHAPTER 2}

Keywords: unconventional PAPR, breath response, HCWs, user preference, acceptance 


\subsection{Introduction}

Healthcare workers (HCWs) are often first responders when there is an outbreak of infected disease such as SARS in 2003, influenza in 2009 and Ebola in 2014. Personal protective equipment (PPE) are critical for people who are working in healthcare field. The Occupational Safety and Health Administration (OSHA) requires all healthcare operations to provide employee protection against blood borne pathogens. Respirators are recommended by the Centers for Disease Control and Prevention (CDC) (2009), OSHA $(2003,2004)$ and the National Institute for Occupational Safety and Health (NIOSH) as an effective way to decrease the risk of infectious exposure. Rebmann et al. (2009) studied that pandemics also require a long-term use of facepiece respirators (N95) for HCWs. However, studies in Rebmann et al. (2009) and Radonvich et al. (2009) had proved that N95 facepiece respirators are not adequate to protect HCWs during an influenza pandemic. So, some guidance was developed by CDC (2006) and OSHA (2010) to address this issue. In addition, the Institute of Medicine (IOM) suggested that wearing a surgical mask over a N95 can provide more protection for HCWs as well as extend the using life of N95.

There are several methods to evaluate the efficiency of a respirator. The assigned protection factor (APF) is defined by OSHA as the respiratory protection level in a workplace that respirators can provide when an employer enrolls in a continuous and effective respiratory protection program offered by the company. The APF for a N95 
respirator is 10 and for powered air purifying respirator (PAPR) is 25 according to OSHA. The maximum use concentration (MUC) is another methodology to assess the respirators.

The MUC is the maximum concentration in a hazardous environment that an employee will be protected from when wearing a respirator. The MUC is calculated by multiplying the APF of the respirator by the permissible exposure limit (PEL) (Steelnack, 2007). Baugh (2015) proposed to use the total inward leakage (TIL) to evaluate the efficiency of the respirator. While TIL could be affected significantly by particle size, breathing flow rate and combustion material (He et al. 2013). Fit test is an important test for making sure that respirators can really protect the users.

The general fit testing procedures given by OSHA include several steps, such as making sure the user properly puts the respirator on, letting the testing subject choose the most acceptable ones. The researches in evaluating the efficiency and protection of N95 respirators under various situations are fully studied by pioneers. Lee et al. (2008) conducted an experiment to determine the protection factors of four different N95 respirator models and surgical masks against particles which the aerodynamic size is about $0.04-1.3 \mu \mathrm{m}$ and very close to bacterial and viral size ranges. As we know, some serious infectious disease such as SARS, H5N1, their particle size range is $0.08-0.86 \mu \mathrm{m}$. This study measured the particle concentrations inside and outside an N95 respirator by using an electrical low-pressure impactor which measures the aerodynamic size of 
particles ranging from $0.029-10.18 \mu \mathrm{m}$. Then the protection factor was the proportion of particle concentration outside of the N95 respirators and inside the mask. Results showed that when the particle size was $0.08-0.2 \mu \mathrm{m}, \mathrm{N} 95$ had the lowest protection factor. Also, about $29 \%$ of $\mathrm{N} 95$ respirators had the protection factors less than 10 which is the required protection level by OSHA. This study indicated that N95 respirators demonstrated a lower efficiency against bacterial and virus than expected.

However, the protection efficiency offered by respirators may be counteracted by the physiological and psychological impact (Szeinuk et al. 2000). So, users' comfort is one the most important factor of evaluating the effectiveness of a respirator. Ideally, HCWs should wear respirators during their daily work without any disturbance and discomfort. There is a number of studies about the perceived intolerance, physiologic impacts of N95 on HCWs. Numerous previous studies showed that due to certain factors, respirator user non-compliance is common and current N95 respirators in the United States market were related to some discomforts such as headaches (IOM, 2008), thermal discomfort (Li et al., 2005; Terrell PG, 1984; Bryce et al., 2008 ), eye discomfort (Eck, Vannier, 1997), vocal and auditory diminish (Akbar-Khanzadeh et al., 1995; Bryce et al., 2008), excessive humidity(Radonovic et al., 2009), facial pressure (IOM, 2008;

Radonovic et al., 2009), and interference with duties (IOM,2001; IOM, 2006). Among those discomforts, facial heat and humidity is one of the most frequent complaints by the N95 respirator users. In study of Roberge et al., (2012), they conducted some tests on 
recording the changes of facial skin temperature under a N95 FFR when subjects were performing tasks for 1 to 2 hours at a low-moderate work rate on a treadmill. Core and skin temperatures were monitored by some sensors. This research indicated that facial skin temperature under the FFR had significantly increased and wearing N95 respirators for 1-2 hours (short term) at low work rate wouldn't add too much thermal burden on subjects. In addition, Roberge et al., (2010) had also proved that N95 FFR didn't impose significant physiological burden during 1 hour use as well as that the exhalation valve cannot relieve N95 FFR's moisture retention and exertion on HCWs.

In further research, as reported in the research of Lu-Yao et al., they recruited 27 HCWs to randomly don 8 different respirators as long as she or he can tolerant the impact of respirators while performing their occupational duties. More than $69 \%$ of participants were not willing to wear those respirators for the entire 8 hours work shift even there was some breaks during the test. Those were experienced intolerance before 8 hours reported several reasons such as diminished communication acuity, facial heat and pressure. Coincidently, long term use of N95 was probed to be associated with headaches and also can induce physiological stress and physical discomfort (Lim et al., (2006)). In general, facial heat and humidity and overall discomfort would increase with time as well as workload. Not only had numerous studies on physiological effects of N95 FFRs, papers were also published with regarding the features that influence the compliance of N95 respirators. A survey study was designed by Aliya et al., (2009) to evaluate the 
respirators use from HCWs views and explore the features they prefer. Survey results indicated that HCWs were looking for respirators which were more comfortable, less interference with duties and lower facial heat. Current respirators need be modified and improved to better meet the requirements of HCWs.

From the previous study we did in chapter 1 , it was already known that the highest penetration rate of the unconventional PAPR Koken respirator under flow rate of $85 \mathrm{~L} / \mathrm{min}$ was $0.194 \%$ when there was a $2 \mathrm{~mm}$ needle leakage. While the APF for half mask PAPR is 50 determined by NIOSH. Even at the flow rate of $115 \mathrm{~L} / \mathrm{min}$, the total penetration was under $5 \%(2.1 \%$ at constant flow $115 \mathrm{~L} / \mathrm{min} ; 3.9 \%$ at cyclic MIF of 115 $\mathrm{L} / \mathrm{min}$ ), which means that the efficiency of this Koken respirator is within (possibly better than) the protection range of a typical N95. On top of efficiency, a laboratory study was conducted by Powell et al., (2017) to evaluate the thermal sensations and comfort of PAPR on HCWs. They recruited 12 subjects to wear five respirators, including one N95 and four types of PAPR. Each subject was donned respirators and walked on a treadmill for one hour at speed of $5.6 \mathrm{~km} / \mathrm{hr}$ which was deemed as low to moderate workload for HCWs. The results showed that under experiment condition, no significant difference was noted on heart rate, respiratory rate, oxygen saturation, transcutaneous $\mathrm{CO} 2$ among these five respirators. However, compared to PAPRs, N95 had much higher respirator dead space heat and humidity. 
Furthermore, Baig et al., (2010) had probed the features of respirators that influences users' compliance and proved that some new characteristics such as no fit testing, allowing facial hair were desired to satisfy the specific requirements of HCWs. The research indicated that $\mathrm{HCWs}$ preferred respirators that more comfortable, less interference with breathing, less facial heat and friend to facial hair. Since the efficiency of Koken PAPR is much higher than N95, the objective of this study was to evaluate the user perception and preference of this unconventional Koken PAPR to see if this respirator is more preferable by HCWs. Results of this study can be useful for HCWs when choosing PAPRs as well as for manufacturs to improve the design of PAPRs.

\subsection{Methods}

\subsubsection{Participants}

Thirty-three subjects age range from 18 to 55 ; non-smoking and no beard from Ruby Memorial Hospital in Morgantown, WV were selected to participate in this study. Those interested would be invited to contact Dr. Anna Allen (Clinical Professor, WVU Hospital) for a medical screen using the OSHA Respirator Medical Evaluation Questionnaire (Appendix A). Participants all were full-time healthcare workers and had used PAPR before. Based on the medical screening questionnaire, those who have used PAPRs previously and for those who were familiar with the twelve tasks described in the questionnaire especially in inserting IV and drawing out blood were selected first. Before 
data collection, subjects were required to be medically cleared for respirator use.

Approvals from the Institutional Review Board (IRB) at the West Virginia University was already obtained and the IRB approval number was 1710808326 .

\subsubsection{Experimental Set-up}

This study was conducted at West Virginia Simulation Training and Education for Patient Safety (WV STEPS) center on WVU's campus on the third floor of the Health Sciences Center (HSC) - South. Subjects performed their tasks in a simulation room which was equipped with a simulated patient: Laerdal SimMan ${ }^{\circledR} 3 \mathrm{G}$ mannequin (male, $85 \mathrm{lb}, 180 \mathrm{~cm}$ ), a bed, sheets, suction device, some monitoring devices, and other medical equipment such as stethoscopes, intravenous (IV) bags, syringes and so on. (Figure 1). Computerized manikin can mimic a real patient such as blinking, breathing and generating heartbeat and other signs that was needed in different scenarios. 


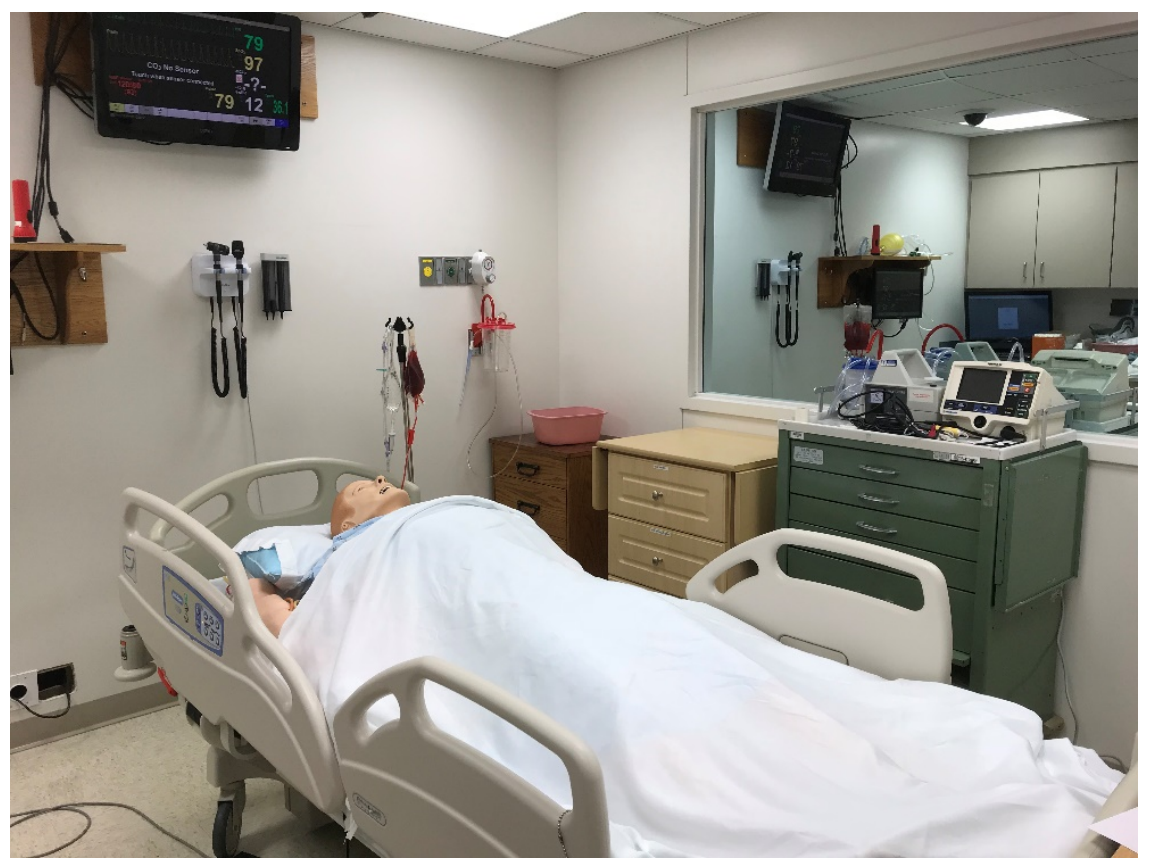

Figure 2. 1 Simulation room setup

Two different respirators were tested in this study. One was 3MTM N95 FFR 8210, as shown in Figure 2.2. It has an adjustable nose clip and advanced electrostatic media. It is disposable, but lighter and relatively inexpensive than PAPRs. The other respirator was Koken ${ }^{\mathrm{TM}}$ breath-response PAPR Model BL-100U (see Figure 2.3). It has a higher protection level and can cool down facial heat, but it is more expensive than N95.

Subjects were donned with these two respirators randomly and asked to perform twelve tasks in order (see Table2.1). Those tasks were designed according to nurses' daily work duties. Before and after each test of a respirator, subject vitals including heart rate, blood oxygen levels and respiratory rate were recorded. Heart rate and blood oxygen were measured by a Nellcor OxiMax N-65 pulse oximeter. Respiratory rate was counted 
by the subject in one minute. After each test, subjects were asked to fill out a questionnaire (Appendix B).

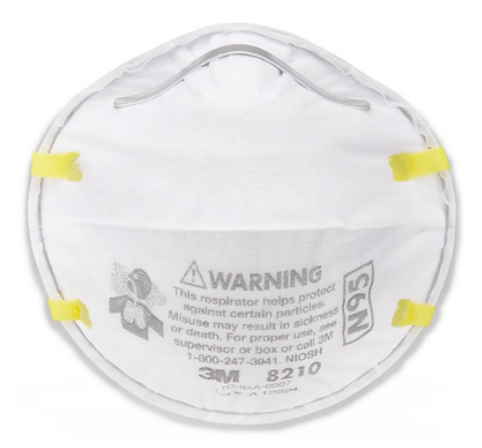

Figure 2. $23 \mathrm{M}^{\mathrm{TM}} \mathrm{N} 95 \mathrm{FFR}$ (from $3 \mathrm{M}$ website)

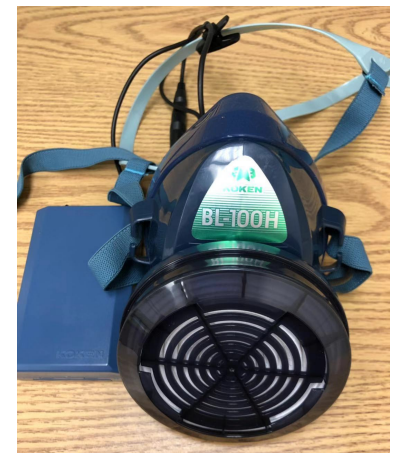

Figure 2. 3 Koken breath-response PAPR

Table 2.1 List and explanation of twelve tasks in the test

\begin{tabular}{|c|c|}
\hline Tasks & Description \\
\hline Setting up bedding/room & $\begin{array}{c}\text { adjust the sheets, add/fold blankets, } \\
\text { putting a pillow under patient's head if } \\
\text { needed, organize room. }\end{array}$ \\
\hline
\end{tabular}




\begin{tabular}{|c|c|}
\hline & Description \\
\hline Insert IV & $\begin{array}{c}\text { Use a stethoscope to listen to patient's } \\
\text { breathing, take pulse in the neck and } \\
\text { feet, check the pupils and ask patient } \\
\text { some basic questions. }\end{array}$ \\
\hline
\end{tabular}




\begin{tabular}{|c|c|}
\hline & Description \\
\hline Insert and set up Foley & $\begin{array}{c}\text { Set up IV bag, attach tubing to IV bag } \\
\text { and start the IV equipment. }\end{array}$ \\
\hline & $\begin{array}{r}\text { Lubricate tubing, clean and insert } \\
\text { tubing into patient. Hang the urine bag } \\
\text { under the corner of bed. }\end{array}$ \\
\hline \\
\hline
\end{tabular}




\begin{tabular}{|l|l|}
\hline & \multicolumn{1}{|c|}{ Description } \\
\hline
\end{tabular}




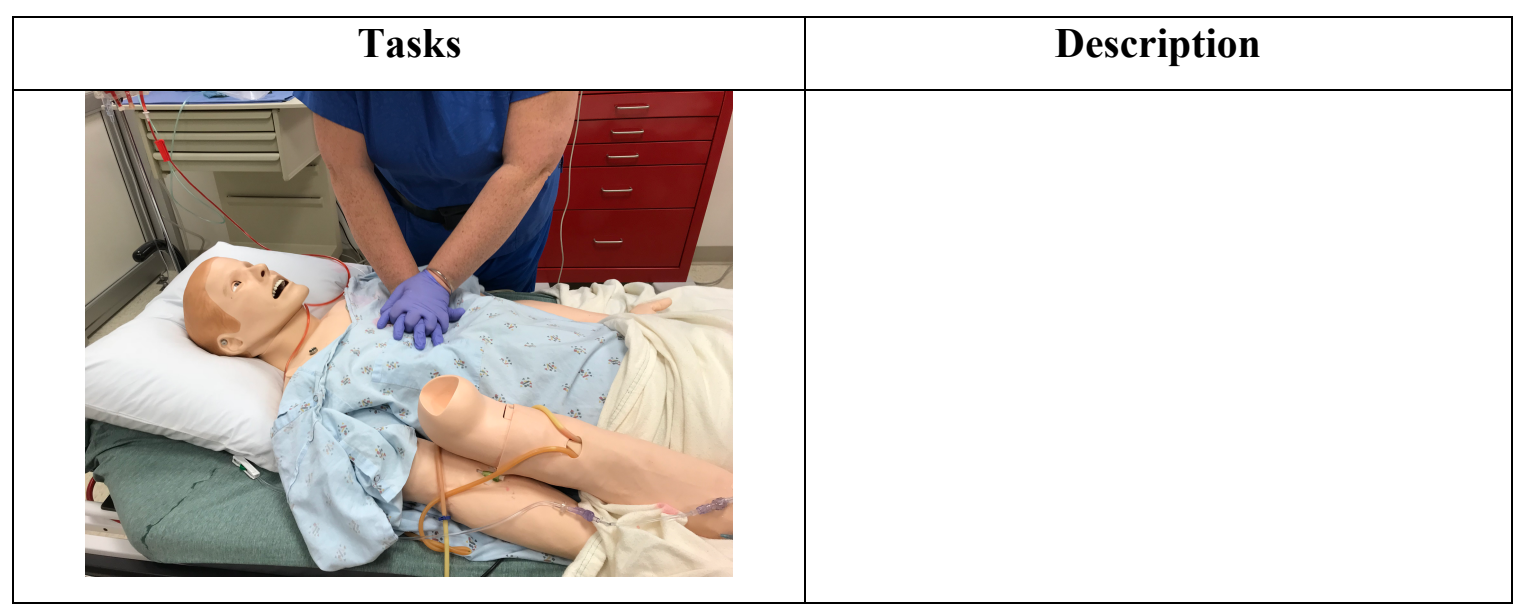

\subsubsection{Experimental Set-up}

After completed twelve tasks, HCWs were required to subjectively evaluate different parameters for the Koken PAPR or N95 FFR using different scales in a questionnaire. The survey contains some basic information such as gender, weight, years of working experience, job title, experience of using respirators about the subject and start and stop times for each respirator were also recorded manually. The subjects chose on the scale for each parameter (16 categories in total). Sixteen categories and six preference questions were explained in table 2.2 and 2.3 .

Table 2.2 Parameters for Evaluation (scales were explained)

\begin{tabular}{|c|c|}
\hline Category & Scale \\
\hline & $\mathbf{1}-\mathbf{6}$ with: \\
& $1-$ Very poor \\
General comfort & $2-$ Poor \\
& $3-$ Acceptable \\
& $4-$ Good \\
& $5-$ Very good \\
& $6-$ Excellent \\
\hline \multirow{2}{*}{ Inspiratory/expiratory effort } & $\mathbf{1 - 7 \text { with: }}$ \\
& $1-$ Not noticeable \\
& $7-$ Intolerable \\
\hline
\end{tabular}




\begin{tabular}{|c|c|}
\hline Category & Scale \\
\hline Overall breathing discomfort & $\begin{array}{c}\text { 1-6 with: } \\
1-\text { Not at all } \\
2-\text { Very slight } \\
3-\text { Slight } \\
4-\text { Somewhat high } \\
5-\text { High } \\
6 \text { - Unbearable } \\
\end{array}$ \\
\hline Facial and body heat & $\begin{array}{c}\text { 1-6 with: } \\
1-\text { Not at all } \\
2-\text { Very slight } \\
3-\text { Slight } \\
4-\text { Somewhat high } \\
5-\text { High } \\
6 \text { - Unbearable } \\
\end{array}$ \\
\hline Overall thermal comfort & $\begin{array}{l}\text { 1-10 with: } \\
1 \text { - Coldest you've ever been } \\
5 \text { - Neither hot nor cold } \\
10-\text { Hottest you have ever been }\end{array}$ \\
\hline Pressure or pain & $\begin{array}{c}1-\mathbf{6} \text { with: } \\
1-\text { Not at all } \\
2-\text { Very slight } \\
3-\text { Slight } \\
4-\text { Somewhat high } \\
5-\text { High } \\
6-\text { Unbearable }\end{array}$ \\
\hline Eye discomfort & $\begin{array}{c}\text { 1-6 with: } \\
1 \text { - Not at all } \\
\text { 2-Very slight } \\
\text { 3- Slight } \\
\text { 4-Somewhat high } \\
\text { 5- High } \\
\text { 6-Unbearable }\end{array}$ \\
\hline $\begin{array}{l}\text { Interference with wearing } \\
\text { glasses/goggles contact lenses } \\
\text { (This was not completed if } \\
\text { subject does not wear these.) }\end{array}$ & $\begin{array}{l}\text { 1-6 with: } \\
1-\text { Not at all } \\
2-\text { Very slight } \\
\text { 3- Slight } \\
\text { 4-Somewhat high } \\
\text { - - High } \\
\text { 6- Unbearable } \\
\end{array}$ \\
\hline
\end{tabular}




\begin{tabular}{|c|c|}
\hline Category & Scale \\
\hline Clear line of vision & $\begin{array}{c}\text { 1-6 with: } \\
1 \text { - Very poor } \\
\text { 2- Poor } \\
3-\text { Acceptable } \\
\text { 4- Good } \\
\text { 5- Very good } \\
\text { 6- Excellent } \\
\end{array}$ \\
\hline Difficulty of putting on & $\begin{array}{c}\text { 1-6 with: } \\
1-\text { Not at all } \\
2-\text { Very slight } \\
\text { 3- Slight } \\
\text { 4-Somewhat high } \\
\text { 5- High } \\
\text { 6-Unbearable }\end{array}$ \\
\hline Difficulty to operate & $\begin{array}{c}\text { 1-6 with: } \\
1 \text { - Not at all } \\
\text { 2-Very slight } \\
\text { 3- Slight } \\
\text { 4-Somewhat high } \\
\text { 5- High } \\
\text { 6-Unbearable } \\
\end{array}$ \\
\hline $\begin{array}{c}\text { Mechanical interference with } \\
\text { duties }\end{array}$ & $\begin{array}{c}\text { 1-6 with: } \\
1 \text { - Not at all } \\
2-\text { Very slight } \\
\text { 3- Slight } \\
\text { 4-Somewhat high } \\
5 \text { - High } \\
\text { 6- Unbearable }\end{array}$ \\
\hline Exertion & $\begin{array}{c}\text { 6- 20 with: } \\
6 \text { - No exertion at all } \\
20-\text { Maximal exertion }\end{array}$ \\
\hline $\begin{array}{l}\text { How many hours do you think } \\
\text { you could wear this respirator } \\
\text { continuously? }\end{array}$ & Written response \\
\hline $\begin{array}{l}\text { Perceived efficiency against } \\
\text { biological hazards }\end{array}$ & $\begin{array}{c}\text { 1-6 with: } \\
1 \text { - Not at all } \\
\text { 2-Very slight } \\
\text { 3-Slight } \\
\text { 4-Somewhat high } \\
\text { 5- High } \\
\text { 6-Complete }\end{array}$ \\
\hline
\end{tabular}




\begin{tabular}{|c|c|}
\hline Category & Scale \\
\hline & $\mathbf{1 - 6}$ with: \\
& $1-$ Not at all \\
& $2-$ Very slight \\
Overall assessment & $3-$ Slight \\
& $4-$ Somewhat high \\
& $5-$ High \\
& $6-$ Unbearable \\
\hline
\end{tabular}

Table 2.3 Preference evaluation questions

\begin{tabular}{|l|l|}
\hline \multicolumn{1}{|c|}{ Question } & \multicolumn{1}{|c|}{ Type of response } \\
\hline $\begin{array}{l}\text { When performing the following tasks (deemed low risks), which } \\
\text { type of the following 2 respirators do you prefer to use? }\end{array}$ & Choose one of the respirators \\
\hline $\begin{array}{l}\text { When performing the following tasks (deemed low risks), which } \\
\text { type of the following 2 respirators do you think is more } \\
\text { acceptable? }\end{array}$ & Choose one of the respirators \\
\hline $\begin{array}{l}\text { When performing the following tasks (deemed low risks), which } \\
\text { type of the following } 2 \text { respirators do you think is more effective? }\end{array}$ & Choose one of the respirators \\
\hline $\begin{array}{l}\text { When performing the following tasks (deemed high risks), which } \\
\text { type of the following } 2 \text { respirators do you prefer to use? }\end{array}$ & Choose one of the respirators \\
\hline $\begin{array}{l}\text { When performing the following tasks (deemed high risks), which } \\
\text { type of the following } 2 \text { respirators do you do you think is more } \\
\text { acceptable? }\end{array}$ & Choose one of the respirators \\
\hline $\begin{array}{l}\text { When performing the following tasks (deemed high risks), which } \\
\text { type of the following 2 respirators do you think is more effective? }\end{array}$ & Choose one of the respirators \\
\hline
\end{tabular}

Note: 1. Consider contact with the patient, blood or body fluids, or coughing as high-risk exposures; 
2. Tasks such as position or assess patient, insert IV, start IV equipment indicate potential low-risk exposure.

\subsection{Data Analysis}

All data from the survey were reorganized in Excel sheets first and separated into two categories: categorical data and numerical data. Categorical data is the part of scaled

data and "yes" or "no" responses based on the preference questions. Numerical data is the part of collecting vital signs. All data was analyzed in R Studio.

\subsubsection{Categorical Data Analysis}

A total of sixteen categories that used to evaluate the respirators. Non-parametric test Kruskal-Wallis test was applied. The Kruskal-Wallis test is a rank-based test that is similar to the Mann-Whitney U test, but it can be applied to one-way data with more than two groups. The test is useful to compare the scores or ratings from multiple speakers, presentations, or groups of audiences. An $\alpha$-level was set to 0.05 .

For the questionnaire data of flow rate preference questions, frequency percentages are calculated. Chi square goodness of fit test was employed to predict if there was a preference on respirators comparing low flow rates with high flow rates facing low or high-risk tasks.

\subsubsection{Numerical Data Analysis}


Numerical data such as heart rate, respiratory rate and blood oxygen levels were collected before and after using respirators. Paired $t$ test was applied to compare whether these two respirators were significantly different from each other. ANOVA table also would be performed. The significance level $\alpha$ was 0.05 as well.

\subsection{Results and Discussion}

\subsubsection{Evaluation on Sixteen Categories}

Two respirators were evaluated by thirty-three HCWs from sixteen different categories. A summary of statistical results such as mean values, standard deviation, maximum and minimum value for evaluation variables was listed in Table 2.4 and 2.5. 
Table 2.4 the Unconventional PAPR Evaluation Statistical Results

\begin{tabular}{|l|c|c|c|c|}
\hline \multicolumn{1}{|c|}{ Category } & Mean & Standard Deviation & Minimum & Maximum \\
\hline General comfort & 2.818 & 1.564 & 1 & 6 \\
\hline Inspiratory/expiratory effort & 3.273 & 1.774 & 1 & 6 \\
\hline Overall breathing discomfort & 2.636 & 1.351 & 1 & 5 \\
\hline Facial and body heat & 2.758 & 1.341 & 1 & 5 \\
\hline Overall thermal comfort & 5.636 & 1.283 & 1 & 8 \\
\hline Pressure or pain & 2.667 & 1.301 & 1 & 5 \\
\hline Eye discomfort & 1.576 & 1.116 & 1 & 5 \\
\hline $\begin{array}{l}\text { Interference with wearing } \\
\text { glasses/goggles/contacts }\end{array}$ & 2.391 & 1.530 & 1 & 5 \\
\hline Clear line of vision & 4.364 & 1.380 & 2 & 6 \\
\hline Difficulty of putting on & 3.000 & 1.169 & 1 & 5 \\
\hline Difficulty to operate & 1.969 & 1.211 & 1 & 4 \\
\hline Mechanical interference with duties & 2.813 & 1.485 & 1 & 6 \\
\hline Exertion & 9.656 & 3.090 & 6 & 16 \\
\hline $\begin{array}{l}\text { How many hours could you wear this } \\
\text { respirator continuously? }\end{array}$ & 2.069 & 0.842 & 1 & 4 \\
\hline $\begin{array}{l}\text { Perceived efficiency against biological } \\
\text { hazards }\end{array}$ & 3.606 & 1.235 & 1 & 5 \\
\hline Overall assessment & 3.091 & 1.326 & 1 & 6 \\
\hline
\end{tabular}


Table 2.5 N95 FFR Evaluation Statistical Results

\begin{tabular}{|l|c|c|c|c|}
\hline \multicolumn{1}{|c|}{ Category } & Mean & Standard Deviation & Minimum & Maximum \\
\hline General comfort & 2.545 & 1.177 & 1 & 5 \\
\hline Inspiratory/expiratory effort & 3.515 & 1.589 & 1 & 7 \\
\hline Overall breathing discomfort & 3.121 & 1.293 & 1 & 5 \\
\hline Facial and body heat & 3.879 & 1.293 & 1 & 6 \\
\hline Overall thermal comfort & 6.636 & 1.410 & 3 & 10 \\
\hline Pressure or pain & 2.848 & 1.223 & 1 & 5 \\
\hline Eye discomfort & 1.667 & 1.160 & 1 & 4 \\
\hline $\begin{array}{l}\text { Interference with wearing } \\
\text { glasses/goggles/contacts }\end{array}$ & 2.522 & 1.951 & 1 & 8 \\
\hline Clear line of vision & 4.667 & 1.226 & 2 & 6 \\
\hline Difficulty of putting on & 1.727 & 1.064 & 1 & 5 \\
\hline Difficulty to operate & 1.182 & 0.454 & 1 & 3 \\
\hline Mechanical interference with duties & 1.394 & 0.803 & 1 & 4 \\
\hline Exertion & 9.515 & 2.961 & 6 & 16 \\
\hline $\begin{array}{l}\text { How many hours could you wear this } \\
\text { respirator continuously? }\end{array}$ & 1.903 & 0.817 & 0 & 4 \\
\hline $\begin{array}{l}\text { Perceived efficiency against biological } \\
\text { hazards }\end{array}$ & 3.485 & 1.338 & 1 & 6 \\
\hline Overall assessment & 3.909 & 1.176 & 1 & 6 \\
\hline
\end{tabular}

The general comfort and clear line of vision had the scale from 1 to 6 , with 6 being the best choice and 1 being the least. Inspiratory/expiratory effort was scaled from 1 to 7 and 1 was the best and 7 was the worst. The scale of other categories such as overall breathing discomfort, facial and body heat, pressure or pain, eye discomfort, interference with wearing glasses/goggles/contact lenses if they have, difficulty of putting on, difficulty to operate, mechanical interference with duties, perceived efficiency against biological hazards and overall assessment was from 1 to 6.1 was the best and 6 was the 
worst. Overall thermal comfort ranged from 1 to 10 with 5 ranking the most comfortable. The range of Exertion was from 6 to 20.6 indicated no exertion and 20 was the maximum exertion. The question "How many hours do you think you could wear this respirator continuously?" was a written response with a higher number being best. The largest number was twelve hours reported by a subject when wearing N95 and she answered that she can wear the tested unconventional PAPR for half an hour, and the smallest hour was 0 hour since this subject felt N95 was too hot and too tight for her and the corresponding wearing time for Koken PAPR was 2 hours. But when analyzing this data, in order to be consistent with the previous 15 ordinal variables, another scale of 1 to 4 was manually assigned: when number of hours was less than 1 hour, a number of 1 was set; when number of wearing hours was greater than 1 less than 2, score was 2; answer was greater than 3 less than 4 , score was set to 3 . And any numbers greater than 4 was set to 4 .

From statistics summary data, we can see there was a big difference between Koken PAPR and N95 FFR on facial and body heat. The mean of unconventional PAPR (Koken PAPR) was 2.76 while the mean of N95 was 3.88 . On overall thermal comfort, the mean of Koken PAPR was 5.67 which was much lower than N95 (6.64), however, the mean of category mechanical interference with duties was higher than N95.

A nonparametric test of Kruskall-Wallis test was performed in R studio. The results are shown in the table below (see Table 2.6). 
Table 2.6 Global test results when comparing the unconventional PAPR with N95

\begin{tabular}{|c|c|c|c|}
\hline Variable & chi-squared & DF & P value \\
\hline General comfort & 0.0649 & 1 & 0.7989 \\
\hline Inspiratory/expiratory effort & 0.3782 & 1 & 0.5386 \\
\hline Overall breathing discomfort & 2.0968 & 1 & 0.1476 \\
\hline Facial and body heat & 8.9646 & 1 & 0.0028 \\
\hline Overall thermal discomfort & 7.8637 & 1 & 0.0050 \\
\hline Pressure or pain & 0.2790 & 1 & 0.5974 \\
\hline Eye discomfort & 0.1078 & 1 & 0.7427 \\
\hline $\begin{array}{c}\text { Interference with wearing } \\
\text { glasses/goggles/contacts }\end{array}$ & 0.0052 & 1 & 0.9423 \\
\hline Clear line of vision & 0.6352 & 1 & 0.4255 \\
\hline Difficulty of putting on & 17.5340 & 1 & 0.0000 \\
\hline Difficulty to operate & 10.3430 & 1 & 0.0013 \\
\hline Mechanical interference with duties & 23.2020 & 1 & 0.0000 \\
\hline Exertion & 0.0085 & 1 & 0.9265 \\
\hline Perceived efficiency against biological hazards & 0.0721 & 1 & 0.7882 \\
\hline Overall assessment & 5.8373 & 1 & 0.0157 \\
\hline
\end{tabular}

The results from Table 2.6 indicated that from aspects of facial and body heat, overall thermal comfort, difficulty of putting on, difficulty to operate, mechanical interference with duties and overall assessment, this unconventional PAPR was significantly different from the tested 3M N95 $(\mathrm{P}<0.05)$. On facial and body heat, and overall thermal discomfort, HCWs were more preferred on Koken PAPR since the mean evaluation score 2.76 was much lower than N95 of 3.88 which was consistent with the study in Powell, et al. (2017) that the deadspace of N95 had some higher heat and humidity. Studies conducted by Roberge et al., (2012) showed that the temperature of the facial skin when wearing N95 masks increased significantly over time. It was easy to understand because PAPR will blow cooling air into the respirator which can make 
wearers feel less heat. However, HCWs thought that this unconventional PAPR was more difficult to put on $($ Mean=3.000, $\mathrm{P}$ value $=0.000)$ and operate $($ Mean $=1.727, \mathrm{P}$ value $=0.0013$ ) when comparing with the tested 3M N95. Meanwhile, Koken PAPR had more interference on their duties (PAPR: Mean=2.813, N95: Mean=1.394; P value $=0.000$ ). As recorded during the experiments, five subjects out of thirty-three reported that their patients may feel anxious when they were performing tasks with this respirator in front of the patients because the respirator would generate different level of noise, sometimes it was loud and sometime light which made them feel annoyed.

Although statistically, on other ten categories, the tested unconventional PAPR did not significantly differ from N95, on overall assessment, the unconventional PAPR had a better score (Mean=3.091, P value=0.0157) than N95 (Mean=3.909).

\subsubsection{Physiology Data Analysis}

Figure 2.4 represented the change in physiological sign such as heart rate (HR), respiratory rate (RR) and blood oxygen level (SpO2) of HCWs before and after each respirator test. Paired t-test was performed and can be found in Table 2.7. 


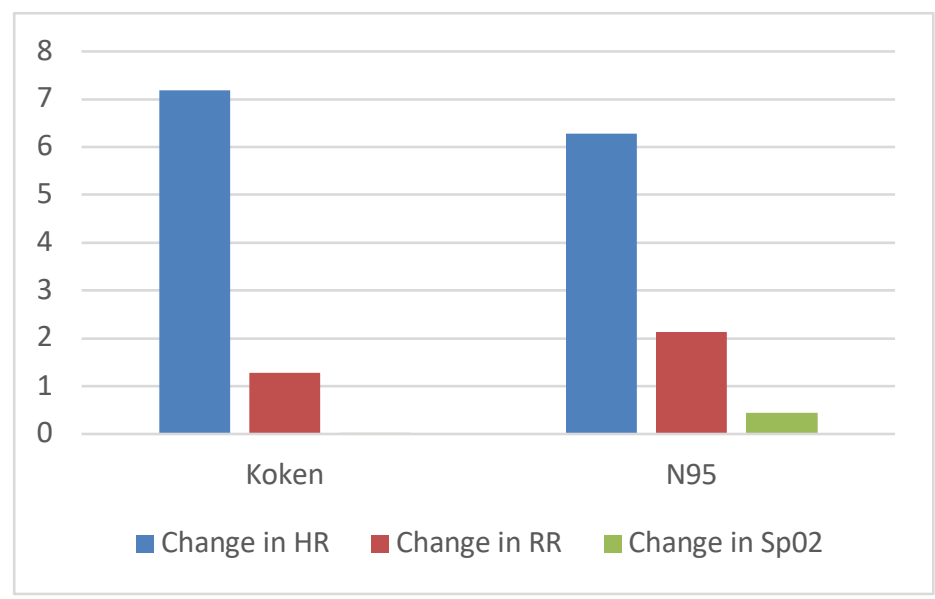

Figure 2.4 Vita sign change before and after the test

Table 2.7 Paired t test results of physiological change of HCWs

\begin{tabular}{lll}
\hline Respirator & Vital Sign before and after & paried t test p-value \\
\hline Koken & Heart Rate & $0.000^{*}$ \\
& Respiratory Rate & $0.014^{*}$ \\
& Sp02 & 0.860 \\
\hline N95 & Heart Rate & $0.001^{*}$ \\
& Respiratory Rate & $0.000^{*}$ \\
& Sp02 & 0.070 \\
\hline
\end{tabular}

Note: * represent these five respirators are different at significance level $\mathrm{a}=0.05$

Both heart rate and respiratory rate were significant changed after the test. Blood oxygen level produced no significant results in two respirators. However, in the study of Powell et al., (2017), they found no significant difference between tested N95 and PAPRs upon $\mathrm{HH}, \mathrm{HR}$ and $\mathrm{SpO}$. One possible reason was that we took the cardiopulmonary signs before the test when subjects were in peaceful condition, while we re-measured those signs after finishing the task of two minutes CPR. It was reasonable that heart rate and respiratory changed due to the activity.

\subsubsection{Preference Analysis}


The respirator preference when conducting high-risk and low-risk tasks was

summarized in Table 2.8. Also, symptoms of nausea, dizziness, odor, and eye irritation

were also evaluated.

Table 2.8 Preference, acceptance, and effectiveness about the respirators

\begin{tabular}{|l|l|l|}
\hline Question & Respirator & Percentage \\
\hline $\begin{array}{l}\text { When performing the following tasks (deemed low risks), which type of the } \\
\text { tested respirators do you prefer to use? }\end{array}$ & Koken & $55.56 \%$ \\
\cline { 2 - 3 } & $\mathrm{N} 95$ & $44.44 \%$ \\
\hline $\begin{array}{l}\text { When performing the following tasks (deemed low risks), which type of the } \\
\text { tested respirators do you think is more acceptable? }\end{array}$ & Koken & $12.5 \%$ \\
\cline { 2 - 3 } $\begin{array}{l}\text { When performing the following tasks (deemed low risks), which type of the } \\
\text { tested respirators do you think is more effective? }\end{array}$ & Koken & $87.5 \%$ \\
\cline { 2 - 3 } & N95 & $57.14 \%$ \\
\hline When performing the following tasks (deemed high risks), which type of the & Koken & $42.86 \%$ \\
\cline { 2 - 3 } tested respirators do you prefer to use? & N95 & $57.14 \%$ \\
\hline When performing the following tasks (deemed high risks), which type of the & Koken & $20 \%$ \\
\cline { 2 - 3 } tested respirators do you think is more acceptable? & N95 & $80 \%$ \\
\hline \multirow{2}{*}{$\begin{array}{l}\text { When performing the following tasks (deemed high risks), which type of the } \\
\text { tested respirators do you think is more effective? }\end{array}$} & Koken & $57.14 \%$ \\
\cline { 2 - 3 } & N95 & $42.86 \%$ \\
\hline
\end{tabular}

When asked if conducting either low-risks or high-risks tasks, HCWs' preference on choosing the tested unconventional PAPR and N95 was the same, and they thought both these two respirators could work effectively. However, more than $80 \%$ subjects chose N95 as a more acceptable respirator when deemed low-risk (87.5\%) and high-risk $(80 \%)$ tasks. Eighteen subjects when performing the designed tasks reported that the continuously different level of noise made them uncomfortable.

\subsection{Conclusions}

Facial and body heat and overall thermal was reported as the one of the main reasons for the noncompliance of N95. As suggested by OSHA, PAPR is the best 
recommended respirator for higher degree of protection against airborne particles, while an N95 does protect its users, it was not considered an adequate protection for some disease (Lee, Grinshpun, \& Reponen (2008)). However, when asked if the tested respirators interfered their duties in the study, N95 had less interference and difficulty to put on and operate than the unconventional PAPR. This because the noise from the blower made users felt uncomfortable (Lenhart, Seitz, Trout, \& Bollinger, 2004).

In general, when performing the designed twelve tasks, subjects preferred the unconventional PAPR over N95 FFR in overall assessment due to less heat and humidity. There were five subjects clearly expressed that the reason why they chose this unconventional PAR was that they knew from SARS and Ebla disease, PAPR can provide more protection when dealing with those infectious disease. Heart rate and respiratory rate was significantly increase for two respirators after completing the listed tasks in Table 2.1, but blood oxygen level was not impacted. No matter low-risk or highrisk task would be taken, there was no preference on these two respirators and most subjects thought that both of they can work effectively. However, more than $80 \%$ subjects thought N95 was more acceptable. These results could be useful to standard development organizations, researchers, respiratory protection program managers and end users.

\subsection{Limitation}


One limitation of this study was that subjects wore each respirator for only 20-30

minutes; however, in their duties, they may need to wear the respirator up to eight hours, which may cause more discomfort affecting their perception. Additional research is necessary to evaluate the effectiveness of communication.

\subsection{Acknowledgement}

This study was supported by the National Institute for Occupational Safety and Health (NIOSH). The contract number is \# 200-2017-M-93679.

\subsection{Disclaimer}

The findings and conclusions of this article are those of the authors and do not necessarily represent the views of the National Institute for Occupational Safety and Health. Mention of a commercial product or trade name does not constitute endorsement by the National Institute for Occupational Safety and Health. 


\section{CHAPTER 3}

\section{Study III - Assessing user discomfort, acceptance and perceived protective efficiency of an unconventional breath-response PAPR vs. traditional PAPRs in a healthcare work setting (Aim 3)}

\section{Abstract}

Objectives: To evaluate HCWs' comfort, perceived protective efficiency and preference about an unconventional PAPR comparing to three traditional PAPR models in a simulated healthcare work environment.

Methods: Like Study II, thirty-three full-time healthcare workers were recruited from the West Virginia University healthcare system to participant the study. In each test, subjects were randomly donned one of the four respirators for about 20-30 minutes and performed twelve different tasks on a simulated patient Laerdal SimMan ${ }^{\circledR}$ 3G mannequin (male, $85 \mathrm{lb}, 180 \mathrm{~cm})$. Vital signs were recorded before and after each test. And when completed all the tasks, a survey questionnaire assessment on discomfort, acceptance and perceived protective efficiency related to the tested PAPR was answered by the subjects.

Results: The results indicated that comparing to three traditional PAPRs, this unconventional PAPR had the least general comfort, most inspiratory/expiratory effort and overall breathing discomfort followed by Versaflo. Koken didn’t perform as well as three tested traditional PAPRs in most categories except in the category of difficulty to operate and mechanical interference with duties. Max Air was the most preferable respirator in this study for the reason of being familiar with respirator and its lightweight and comfortable design. 
Keywords: Healthcare workers, unconventional PAPRs, traditional PAPR, user's preference, discomfort 


\subsection{Introduction}

Airborne respiratory infectious diseases may present a life-threatening risk for health care workers (HCWs) during pandemic emergencies as well as exposures during routine aerosolgenerating procedures. The outbreak of some serious infectious pathogens (The 2003 severe acute respiratory syndrome (SARS), 2009 Pandemic Influenza A (H1N1) and the Ebola) brings the importance of using personal protective equipment (PPE) especially respiratory protective equipment to public's attention. The Centers for Disease Control and Prevention (CDC), Occupational Safety and Health Administration (OSHA) and Institute of Medicine (IOM) all state that N95 filtering facepiece respirators (FFR) or higher (N100), or powered air purifying respirators (PAPRs), should be used for close patient contact with influenza and SARS, and PAPRs should be used for aerosol-generating procedures as well as airborne diseases such as tuberculosis.

While N95 FFRs and surgical masks do provide protection against some airborne particles (Food \& Drug Administration), they do not provide enough protections against small virions (Bałazy et al., 2006). When a higher level of protection is required, a powered airpurifying respirator (PAPR) is recommended by OSHA. PAPRs are not limited to use in protection against epidemic infectious disease. Healthcare workers may be subject to exposure to hazardous materials such as chemical, nuclear or biological warfare agents. In addition, there are many industrial chemical and nuclear agents that pose risks to healthcare workers. OSHA recommends the use of PAPRs and body suits as protection for workers in these settings against such agents. OSHA also suggests workers to use PAPRs under the circumstance of having unknown and unquantified hazardous substance (OSHA, 2005). 
One advantage to use PAPRs is that they provide a higher level of protection (assigned protection factor or APF $=25$ for helmet and loosing fitting facepiece PAPR, 50 for half-mask PAPR, 1,000 for full facepiece and hood PAPR) than the N95 FFR (APF $=10)$ because they supply maximally filtered air, eliminate face seal leakage, reduce breathing difficulty encountered in negative pressure air-purifying respirators, and provide contact protection for the head (Wizner et al., 2016). OSHA doesn't require fit testing for loose-fitting PAPRs (OSHA, 2015). The full hood, but not the loose-fitting face cover, may be used by those with a beard. Ameliorating heat related problems through cooling system is another advantage of PAPRs (Fennelly, 1997; Khoo et al., 2005). Blowers in PAPRs can generate positive pressure inside the facepiece which potentially reduces the leakage of contaminated air and also removes some breathing resistance issues. In responding to Ebola epidemic, the National Institute for Occupational Safety and Health (NIOSH) has listed several NIOSH-approved PAPRs as meeting the $\mathrm{CDC}$ criteria for use in managing patients with Ebola. However, the higher protection level that the PPE provides, the greater negative influence on HCWs' comfort (Roberge, et al., 2012; Coca, et al., 2017). There exists an inverse effect between protection and comfort.

Besides APF that used to be evaluate the performance of PAPRs, a study protocol was developed to obtain simulated workplace protection factor (SWPF) for powered air-purifying respirators (PAPRs) and supplied-air respirators (SAR) with hoods and helmets by Cohen et al., (2001) in a simulated workplace. Results indicated that most tested PAPRs could provide efficient protections for workers, except NIOSH-approved SAR provided least protection. Martin et al (2006) also conducted an 8-hour test on 5 PAPRs, four with mechanical filters and one with an electrostatic filter by challenging the dioctyl phthalate (DOP) particles. The results showed that a PAPR with an electrostatic filter had the highest penetration values. The manikin Fit 
Factor (mFF) of an improperly sized or stretched-out loose-fitting PAPR was determined by Gao et al., (2016). They found that the mFF decreased exponentially as the increasing of the mean inspiratory flows under cyclic flow type which meant that PAPR provided significantly less protection than it should do. This study proved that a properly sized PAPR was crucial for subject to provide sufficient protection. Administrators should provide HCWs proper PPE to ensure their employees' health and safety. In Koivisto et al., (2015) study, the program protection factor of a loose-fitting PAPR was tested with challenge aerosol of nanoparticles in a workplace. The PPF was measured using condensation particle counters. And results indicated that the tested PPF was several times higher than its APF 25 and the loose-fitting powered air purifying respirators provide efficient protection against nanoparticle exposure if subjects use them properly.

During the 2003 SARS outbreak, the use of the PAPR was mandatory and widespread. A questionnaire-based survey was conducted by Khoo et al., (2005) on healthcare workers who had ever used the PAPR in clinical practice during the SARS outbreak. Evaluation questions such as perceptions of comfort, ease of use, visual, hearing, and speak interference, perceived protection against SARS and preferences were recorded. A small amount of subjects reported that PAPR was uncomfortable and had some impairment in communication. However, $84 \%$ preferred to use the PAPR rather than the N95 FFR when treating suspected SARS patients. While facing patients with pulmonary tuberculosis, there was no significantly different preference between PAPR and N95 FFR.

Although compared to N95 that PAPRs have some advantages such as more protection and cooling facial area, PAPRs are significantly heavier and more expensive. It is difficult for PAPRs to be applied in sterile fields. Meanwhile, the batteries for the blower must be frequently 
recharged and maintained. Due to the noise caused by the blowers inside the PAPR, communication issues have been reported between HCWs and patients. Sometimes it looks awkward in certain tasks (Lenhart et al., 2004). These disadvantages could possibly prevent HCWs from using PAPRs in their workplaces.

In the meantime, Zamora et al., (2006) pointed that workers wearing PAPR required significantly more time to don and remove the whole respirators, then violated donning procedure guidelines more frequently. Despite trainned by experienced person, a significantly higher number of participants were against the rules while donning PAPRs which could bring HCWs to another uncertain risk as well as decrease the protection level of PAPRs (Crutchfield et al, 1999). A plenty of studies have demonstrated that HCWs are poorly compliant with respiratory protection guidelines (Hammond et al., (1990); Gershon et al., (1995); Evanhoff et al., (1999); Nickell et al., (2004)).

Currently, numerous prior studies have been conducted in the laboratory setting with healthy volunteers to evaluate comfort, tolerance, barriers and user physiological stress of N95 FFRs during exercises or in work settings with HCWs. However, few studies have been performed with HCWs in the actual healthcare work environments to assess discomforts, acceptance and protective efficiency towards wearing and using of PAPRs. There is one study undertaken by Powell et al., (2017) investigating the physiological effects and subjective perceptions of PAPRs that would impact the thermal sensations and comfort. They recruited twelve subjects and tested five different types of respirators including four PAPRs and a N95. N95 FFR had a higher deadspace heat and humidity than PAPRs. On the contrary, the tight fitting PAPR had the highest perception of eye dryness. The results also demonstrated that there was no significant difference between N95 FFR and PAPRs on the effects of heart rate, 
respiratory rate, breathing effort and facial and overall body heat at a low to moderate workload. PAPRs did ameliorate some facial temperature that caused by increasing workload but not improve on facial heat and overall body heat.

There is no previous literature study on if PAPRs are perceived effectively and acceptable to HCWs, and if there are any discomforts that affect the intolerance of use. Therefore, it is essential that these NIOSH certified PAPRs will be evaluated by HCWs during their normal work duties and tasks. PAPR performance over time is of prominent importance in protecting HCWs' health. Worker input about safety devices is an important part of an overall safety program. HCWs in different departments may deal with different work/patient treatment scenarios that have varying risk levels. For instance, caring for patients with highly contagious diseases such as Ebola, SARS Influenza A (H1N1) have a much higher risk than caring for routine patients and common influenza or tuberculosis (TB) patients. In these high-risk work situations, although CDC indicated that both PAPR and N95 FFR can be used, PAPRs provide higher protection to HCWs than N95 FFR and should be a better choice of respiratory protective device (RPD) to use. However, it is not clear based on current literature which type of RPD is preferred by HCWs and if a lower flow rate design of a PAPR will provide less discomfort, more acceptance and similar perceived protective efficiency. Similarly, when low risk patient care work is involved, it is not clear if it is more acceptable and comfortable to HCWs to use PAPRs with a lower flow rate. Such information is very useful and helpful to manufacturers in improving their design of new PAPRs and to end users in compliance with respiratory protection programs.

Therefore, to conduct this study, we are trying to fill in the research gap and evaluate PAPRs with tasks at varying risk levels. The main purpose of this research was to identify the 
differences in discomfort, acceptance and perceived protective efficiency among 4 different types PAPRs (including the unconventional Koken brath-response PAPR) in a simulated healthcare work setting.

\subsection{Methods}

\subsubsection{Respirators}

Four types of PAPRs including three traditional PAPRs and one unconventional PAPR were tested in this study. Their characteristics summary and figures were listed in Table 3.1 and Figure 3.1. Prior to being allowed to participate this study, subjects have to complete a medical screening questionnaire (Appendix A) and fill out the OSHA clearance form. Once they got respirators clearance approval from Dr. Anna Allen (Clinical Professor, WVU Hospital), they were scheduled to start the data collection.

Table 3.1 Four evaluated PAPRs in the study

\begin{tabular}{|c|c|c|c|c|}
\hline Respirator & Type & Characteristics & Flow rate & Weight \\
\hline $\begin{array}{l}\text { MaxAir CAPR } \\
710\end{array}$ & loose-fitting PAPR & $\begin{array}{l}\text { Helmet and double disposable } \\
\text { shroud; provides completed } \\
\text { head and neck protection }\end{array}$ & $\begin{array}{l}\text { adjustable, from } 190 \text { to } \\
240 \mathrm{~L} / \mathrm{min} \text {. }\end{array}$ & $2.5 \mathrm{lb}$ \\
\hline $3 \mathrm{M}$ Versaflo & loose-fitting PAPR & $\begin{array}{l}\text { Hood and shroud soft headed } \\
\text { top }\end{array}$ & $\begin{array}{l}\text { adjustable, from } 185 \text { to } \\
225 \mathrm{~L} / \mathrm{min} \text {. }\end{array}$ & $4.5 \mathrm{lb}$ \\
\hline 3M Air-Mate & loose-fitting PAPR & Headgear & $170 \mathrm{~L} / \mathrm{min}$ & $3.0 \mathrm{lb}$ \\
\hline Koken BL-100U & $\begin{array}{l}\text { Tight-fitting breath } \\
\text { response } \\
\text { elastomeric PAPR }\end{array}$ & $\begin{array}{l}\text { Supplying air according to } \\
\text { user's demand }\end{array}$ & $\begin{array}{l}\text { self-adjustable, up to } \\
103 \mathrm{~L} / \mathrm{min}\end{array}$ & $0.82 \mathrm{lb}$ \\
\hline
\end{tabular}




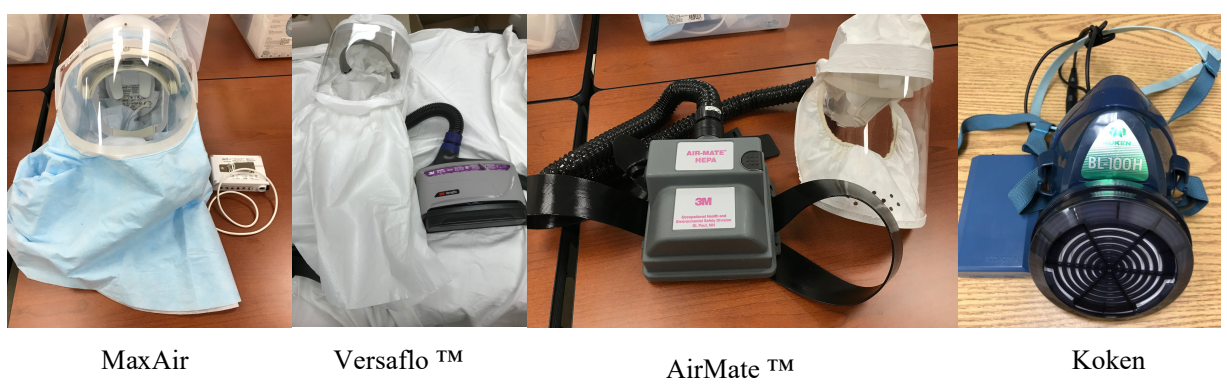

Figure 3.1 Respirators evaluated in this study

\subsubsection{Experimental Set-up}

Thirty-three full-time healthcare workers recruited from the WVU healthcare system participated in the study. The experiment was conducted in the West Virginia Simulation Training and Education for Patient Safety (WV STEPS) center. In each experiment, subjects were randomly donned one of the four respirators for about 20-30 minutes and perform tasks on a simulated patient Laerdal $\operatorname{SimMan}{ }^{\circledR} 3 \mathrm{G}$ mannequin (male, $85 \mathrm{lb}, 180 \mathrm{~cm}$ ). Before starting the test, all subjects were asked to sign a consent form. They were also explained an overview of this experiment and minimal risk level about this study. Then subjects were given a brief introduction and orientation in the simulation room to make sure that subjects fully undersood the purpose of this study, were familiar with the simulation room, and had a general view about the list of tasks so that the evaluation of the first respirator would not be biased.

After this, subject started to don their first PAPR. To reduce the random error, the order of PAPR models was randomized. Subjects' physiological signs (heart rate HH, respiratory rate $\mathrm{RR}$, blood oxygen level $\mathrm{SpO} 2$ ) were measured. Then subjects will be taken to the simulation room and perform assigned tasks listed in the Appendix B. When completed all the tasks, vital signs were recorded again, and a survey questionnaire (Appendix B) assessment on discomfort, acceptance and perceived protective efficiency related to the tested PAPR was answered by the 
subjects. Finally, subjects would also have a compensation after completing evaluating all four PAPRs.

A 6-point scale was used to quantify some subjective impressions of the general comfort ( [1] very poor to [6] excellent), clear line of vision ( [1] very poor to [6] excellent), overall breathing discomfort ( [1] not at all to [6] unbearable), facial and body heat ( [1] not at all to [6] unbearable), pressure or pain ( [1] not at all to [6] unbearable), eye discomfort ( [1] not at all to [6] unbearable), interference with wearing glasses/goggles/contact lenses if they have( [1] not at all to [6] unbearable), difficulty of putting on ( [1] not at all to [6] unbearable), difficulty to operate ( [1] not at all to [6] unbearable), mechanical interference with duties( [1] not at all to [6] unbearable), perceived efficiency against biological hazards( [1] not at all to [6] complete), and overall assessment ( [1] not at all to [6] unbearable). Inspiratory/expiratory effort was evaluated with a 7-point scale ranging from [1] "not noticeable" from [7] "intolerable". A 10-point scale (ranges from [1] coldest you've ever been to [5] neither hot nor cold to [10] hottest you've ever been) was used to quantify the overall thermal comfort level. The range of Exertion was from 6 to 20 with 6 indicating no exertion and 20 was the maximum exertion.

Different PAPRs models have different flow rates. For tested traditional PAPRs, flow rates are set by manufactures, some PAPRs can adjust the flow rate only in a certain value. For example, MaxAir CPAR 710 has three different flow rates $(190 \mathrm{~L} / \mathrm{min}, 215 \mathrm{~L} / \mathrm{min}$, and 240 L/min) for users to adjust. So, this study also evaluated HCWs' preference of current flow rate at different risk level by answering the questions listed in Table 3.2. Other subjective feelings such as nausea, dizziness or difficult concentrating, unusual smell, and eye irritation were also evaluated. 
Table 3.2 Questionnaire survey about user's preference

\begin{tabular}{|c|c|}
\hline \multicolumn{1}{|c|}{ Question } & Type of response \\
\hline $\begin{array}{c}\text { When performing the following tasks (deemed low risks), do you prefer } \\
\text { a lower flow rate for the following PAPR? }\end{array}$ & Yes or No for each respirator \\
\hline $\begin{array}{c}\text { When performing the following tasks (deemed low risks), do you think } \\
\text { a lower flow rate is more acceptable? }\end{array}$ & Yes or No for each respirator \\
\hline $\begin{array}{c}\text { When performing the following tasks (deemed low risks), do you think } \\
\text { a lower flow rate is more effective? }\end{array}$ & Yes or No for each respirator \\
\hline $\begin{array}{c}\text { When performing the following tasks (deemed low risks), which type } \\
\text { of the following four respirators do you prefer to use? }\end{array}$ & Only choose one you prefer \\
\hline $\begin{array}{c}\text { When performing the following tasks (deemed low risks), which type } \\
\text { of the following four respirators do you think is more acceptable? }\end{array}$ & Only choose one you prefer \\
\hline $\begin{array}{c}\text { When performing the following tasks (deemed low risks), which type } \\
\text { of the following four respirators do you think is more effective? }\end{array}$ & Only choose one you prefer \\
\hline $\begin{array}{c}\text { When performing the following tasks (deemed high risks), which type } \\
\text { of the following four respirators do you prefer to use? }\end{array}$ & Only choose one you prefer \\
\hline $\begin{array}{c}\text { When performing the following tasks (deemed high risks), which type } \\
\text { of the following four respirators do you think is more acceptable? }\end{array}$ & Only choose one you prefer \\
\hline $\begin{array}{c}\text { When performing the following tasks (deemed high risks), which type } \\
\text { of the following four respirators do you think is more effective? }\end{array}$ & Only choose one you prefer \\
\hline
\end{tabular}

\subsection{Data Analysis}

Categorical variables were analyzed via a non-parametric test Kruskal-Wallis test in $\mathrm{R}$ studio. Krusal-Wallis test states that there are differences between the groups, but not which group is different from other groups. Thus, a post-hoc test was performed to determine whether a group was different from another. Dunn test was applied as a post-hoc test for the KruskalWallis test. For example, when a significant difference was found in those four tested PAPR with regard to general comfort category, post-hoc multiple comparison testing Dunn test was carried out to identify the mean difference between four PAPR models. Paired t test was conducted to compare the difference change before and after the PAPRs when donned during the tasks.

Statistical $\mathrm{P}$ value of $<0.05$ was considered as significant.

\subsection{Results and Discussion}




\subsubsection{Evaluation on Sixteen Subjective Categories}

Mean values ( \pm one standard deviation) for evaluation variables were presented in Table

3.3. Statistically significant variables were found in Table 3.4 by Krusal-Wallis test.

Table 3.3 Mean \pm standard deviation values of sixteen categories evaluation of four PAPRs

\begin{tabular}{l|llll}
\hline Variable & $\begin{array}{l}\text { MAX AIR } \\
\text { (Mean } \pm \text { SD) }\end{array}$ & $\begin{array}{l}\text { AIR MATE } \\
\text { (Mean } \pm \text { SD) }\end{array}$ & $\begin{array}{l}\text { VERSAFLO } \\
\text { (Mean } \pm \text { SD) }\end{array}$ & $\begin{array}{l}\text { KOKEN } \\
\text { (Mean } \pm \text { SD) }\end{array}$ \\
\hline General comfort & $3.73 \pm 1.09$ & $3.7 \pm 1.06$ & $2.91 \pm 1.21$ & $2.82 \pm 1.56$ \\
Inspiratory/expiratory effort & $1.61 \pm 0.85$ & $1.94 \pm 0.91$ & $2.33 \pm 1.35$ & $3.27 \pm 1.77$ \\
Overall breathing discomfort & $1.33 \pm 0.53$ & $1.61 \pm 0.84$ & $2.03 \pm 1.24$ & $2.64 \pm 1.35$ \\
Facial and body heat & $2.21 \pm 0.98$ & $2.06 \pm 1.00$ & $2.70 \pm 1.50$ & $2.76 \pm 1.34$ \\
Overall thermal discomfort & $5.42 \pm 1.26$ & $4.91 \pm 0.99$ & $5.48 \pm 1.89$ & $5.67 \pm 1.28$ \\
Pressure or pain & $1.88 \pm 1.15$ & $1.61 \pm 0.72$ & $2.00 \pm 1.32$ & $2.67 \pm 1.30$ \\
Eye discomfort & $1.42 \pm 0.1$ & $1.27 \pm 0.78$ & $1.36 \pm 0.67$ & $1.58 \pm 1.11$ \\
$\begin{array}{l}\text { Interference with wearing } \\
\text { glasses/goggles/contacts }\end{array}$ & $2.00 \pm 1.38$ & $1.87 \pm 1.14$ & $1.96 \pm 1.19$ & $2.39 \pm 1.53$ \\
Clear line of vision & $3.97 \pm 1.35$ & $3.94 \pm 1.14$ & $3.48 \pm 0.93$ & $4.36 \pm 1.38$ \\
$\begin{array}{l}\text { Difficulty of putting on } \\
\text { Difficulty to operate }\end{array}$ & $2.27 \pm 0.99$ & $2.76 \pm 0.99$ & $3.15 \pm 1.06$ & $3.00 \pm 1.17$ \\
$\begin{array}{l}\text { Mechanical interference with duties } \\
\text { How many hours could you wear } \\
\text { this respiratory continuously? }\end{array}$ & $1.64 \pm 0.76$ & $2.12 \pm 0.88$ & $2.48 \pm 1.43$ & $1.97 \pm 1.21$ \\
$\begin{array}{l}\text { Exertion } \\
\text { Perceived efficiency against } \\
\text { biological hazards } \\
\text { Overall assessment }\end{array}$ & $2.67 \pm 1.05$ & $2.51 \pm 1.15$ & $3.24 \pm 1.32$ & $2.81 \pm 1.48$ \\
\hline & $2.42 \pm 1.75$ & $2.08 \pm 1.10$ & $1.99 \pm 1.57$ & $1.50 \pm 1.10$ \\
\hline & $8.12 \pm 1.91$ & $8.39 \pm 2.55$ & $9.48 \pm 3.39$ & $9.66 \pm 3.09$ \\
& $3.46 \pm 1.41$ & $3.67 \pm 1.25$ & $3.91 \pm 1.26$ & $3.61 \pm 1.23$ \\
\hline
\end{tabular}


Table 3.4 Krusal-Wallis testing results of four PAPRs

\begin{tabular}{c|ccc}
\hline Variable & chi-squared & DF & P value \\
\hline General comfort & 16.389 & 3 & 0.0009 \\
Inspiratory/expiratory effort & 20.983 & 3 & 0.0001 \\
Overall breathing discomfort & 23.721 & 3 & 0.0000 \\
Facial and body heat & 6.0986 & 3 & 0.1069 \\
Overall thermal discomfort & 7.5425 & 3 & 0.0565 \\
Pressure or pain & 12.856 & 3 & 0.0050 \\
Eye discomfort & 1.8805 & 3 & 0.5976 \\
Interference with wearing & & & \\
glasses/goggles/contacts & 0.61375 & 3 & 0.8933 \\
Clear line of vision & 7.4631 & 3 & 0.0585 \\
Difficulty of putting on & 11.521 & 3 & 0.0092 \\
Difficulty to operate & 8.0249 & 3 & 0.0455 \\
Mechanical interference with duties & 5.6355 & 3 & 0.1308 \\
Exertion & 5.2729 & 3 & 0.1529 \\
Perceived efficiency against biological hazards & 2.2193 & 3 & 0.5282 \\
Overall assessment & 2.6429 & 3 & 0.4500 \\
\hline
\end{tabular}

From the Table 3.4 above, the mean of general comfort of the unconventional PAPR (Koken PAPR) (Mean=2.82) was obviously lower than other three traditional PAPRs, especially Max Air (Mean=3.73) and Air Mate (Mean=3.7) indicating that Koken PAPR had less comfort than traditional PAPRs. The mean values of inspiratory/expiratory effort (Mean=3.27) and overall breathing discomfort $($ Mean=2.64) were much higher than three traditional PAPRs. For the category of clear line of vision, Koken PAPR had the highest mean value. As recorded in questionnaire, one subject thought that she can only wear the Koken PAPR continuously for 0.05 hour which was the lowest time during the four PAPRs and the maximum wearing time was 4 hours. For Max Air, the minimum wearing time was 0.15 hour and maximum was 8 hours. The subjects who answered 0.15 hour said that she cannot bear the heavy helmet for a long time. The minimum continuously wearing time for Air Mate and Versaflo was 0.2 hours, and maximum time for Air mate was 4 hours and for Versaflo was 6 hours. In the convenience of analysis, a 4point scale was designed. When wearing hour was less than 1 hour, a number of 1 was set; 2 
represents the wearing hours greater than 1 less than $2 ; 3$ indicates that wearing time was between 3 hours and 4 hours. And any time longer than four hours was set to 4 .

The Krusal-Wallis test results were shown in Table 3.5. Statistically significant variables were found on categories of general comfort ( $\mathrm{p}=0.0009)$, inspiratory/expiratory effort ( $\mathrm{p}=0.0001)$, overall breathing discomfort $(\mathrm{p}=0.000)$, difficulty putting on $(\mathrm{p}=0.0092)$ and difficult to operate $(\mathrm{p}=0.0455)$. No statistically significant differences were found in facial and body heat $(\mathrm{p}=0.1069)$ and overall thermal discomfort $(\mathrm{p}=0.0565)$ which had the same results as in study of Caretti and Gardner, (2003). It also indicated that wearing PAPR would ameliorate the problem of thermal sensation when comparing with N95 in Study II. Post-hoc Dunn test results were shown in Table 3.5. 
Table 3.5 Post-hoc test results

\begin{tabular}{|c|c|c|c|}
\hline Variable & Comparison & $\mathbf{Z}$ & P value \\
\hline \multirow{6}{*}{ General comfort } & Air Mate - Koken & 3.208 & 0.001 \\
\hline & Air Mate - Max Air & 0.196 & 0.845 \\
\hline & Koken - Max Air & -3.012 & 0.003 \\
\hline & Air Mate - Versflo & 2.653 & 0.008 \\
\hline & Koken- Versflo & -0.555 & 0.579 \\
\hline & Max Air - Versflo & 2.457 & 0.014 \\
\hline \multirow{6}{*}{$\begin{array}{c}\text { Inspiratory/expiratory } \\
\text { effort }\end{array}$} & Air Mate - Koken & -3.106 & 0.002 \\
\hline & Air Mate - Max Air & 1.344 & 0.179 \\
\hline & Koken - Max Air & 4.450 & 0.000 \\
\hline & Air Mate - Versflo & -0.897 & 0.370 \\
\hline & Koken- Versflo & 2.209 & 0.027 \\
\hline & Max Air - Versflo & -2.241 & 0.025 \\
\hline \multirow{6}{*}{$\begin{array}{l}\text { Overall breathing } \\
\text { discomfort }\end{array}$} & Air Mate - Koken & -3.430 & 0.001 \\
\hline & Air Mate - Max Air & -0.979 & 0.327 \\
\hline & Koken - Max Air & 2.451 & 0.014 \\
\hline & Air Mate - Versflo & -0.976 & 0.329 \\
\hline & Koken- Versflo & 2.455 & 0.014 \\
\hline & Max Air - Versflo & 0.004 & 0.997 \\
\hline \multirow{6}{*}{ Difficulty of putting on } & Air Mate - Koken & -0.822 & 0.411 \\
\hline & Air Mate - Max Air & 1.617 & 0.106 \\
\hline & Koken - Max Air & 2.439 & 0.015 \\
\hline & Air Mate - Versflo & -1.626 & 0.104 \\
\hline & Koken- Versflo & -0.804 & 0.422 \\
\hline & Max Air - Versflo & -3.243 & 0.001 \\
\hline
\end{tabular}

With regarding to general comfort evaluation, Koken PAPR was significantly different from Max Air and Air Mate. The mean of Koken PAPR was 2.82 and the mean for Max Air and Air Mate was 3.73, 3.7 respectively. The Max Air and Air Mate were found to be more favorable when compared to the Koken PAPR and Versaflo in general comfort. Similarly, in inspiratory/expiratory effort, Koken PAPR had significant difference from other three traditional PAPRs. The mean value for Koken PAPR was 3.27 which was much higer than Max Air 
(Mean=1.61), Air Mate (Mean=1.94) and Versaflo (Mean=2.33). This indicated that subjects spent more effort on inspiratory/expiratory when wearing Koken PAPR comparing other three tested PAPRs.

On overall breathing discomfort, the Dunn test results indicated that Koken PAPR (Mean=2.64) was rated as the most discomfort PPAR. No significant difference was found between the three traditional PAPRs $(\mathrm{P}>0.05)$. This likely relates to the fact that the highest flow rate of this unconventional PAPR can provide is $103 \mathrm{~L} / \mathrm{min}$, and it supplies air flow according to user's breathing pattern. Comparing to Max Air (Mean =2.27), subjects experienced difficulty of putting on Koken (Mean=3.00, $\mathrm{p}=0.015$ ) and Versaflo (Mean=3.15, $\mathrm{p}=0.001)$. As the subjects reported that they experienced some level of breathing discomfort and burden when wearing the Versaflo. The heavier battery back and the tighter hood can explain this. The extra physical strain due to the heavier battery back may have contributed to the perception of breathing discomfort that the subjects experienced. This possible issue of Versaflo design is very important as it relates to the function and purpose of the PAPR itself.

Although there was no statistically significant difference in overall assessment category, general speaking, Koken didn’t perform as well as three tested traditional PAPRs in most categories except in the category of difficulty to operate and mechanical interference with duties. Max Air was the most preferable one with better scores in most of evaluation categories except in interference with wearing glasses/goggles/contact lenses and mechanical interference with duties. A possible explanation of why many subjects preferred Max Air is that most subjects had used a very similar PAPR before. They already knew how to use this PAPR and were familiar with it. Then there may be bias on it. However, beside those, the lightweight, ease to operate and comfortable design made it favorable. 


\subsubsection{PAPR Flow Rate Preference}

Analysis on evaluating the preference, acceptance, and effectiveness of flow rates as well as respirator preference when conducting high-risk and low-risk tasks was shown in Table 3.6. Also, symptoms of nausea, dizziness, odor, and eye irritation were also evaluated.

In terms of preferring the PAPR have a lower flow rate when conducting low-risk tasks, most of the subjects (>60\%) preferred that all PAPRs did not have a lower flow rate. Similarly, when asked if a lower flow rate was more acceptable, $60.6 \%$ subjects thought that they didn't need lower flow rate for Max Air and Air mate. $42.4 \%$ subjects thought it was more acceptable for a lower flow rate for the Versaflo. And over a half subjects (51.5\%) a lower flow rate for Koken was more acceptable. In addition, when determining whether a lower flow rate was more effective, most of subjects thought a lower flow rate would not be more effective for Max Air $(66.7 \%)$ and Versaflo (60.6\%). However, nearly $50 \%$ of subjects for Air mate and Koken thought lower flow rates would be more effective. 
Table 3.6 PAPR flow rate preference frequency

\begin{tabular}{|c|c|c|c|}
\hline \multirow[t]{2}{*}{ Question } & \multirow[t]{2}{*}{ Respirator } & \multicolumn{2}{|c|}{$\begin{array}{c}\text { Total number (proportion) } \\
\text { of people preference }\end{array}$} \\
\hline & & Yes $(\%)$ & No $(\%)$ \\
\hline \multirow{4}{*}{$\begin{array}{l}\text { When performing the following tasks (deemed low } \\
\text { risks), do you prefer a lower flow rate for the } \\
\text { following PAPR? }\end{array}$} & MAX AIR & $12(36.4)$ & $21(63.6)$ \\
\hline & AIR MATE & $11(33.3)$ & $22(66.7)$ \\
\hline & Versaflo & $12(36.4)$ & $21(63.6)$ \\
\hline & Koken & $13(39.4)$ & $20(60.6)$ \\
\hline \multirow{4}{*}{$\begin{array}{l}\text { When performing the following tasks (deemed low } \\
\text { risks), do you think a lower flow rate is more } \\
\text { acceptable? }\end{array}$} & MAX AIR & $13(39.4)$ & $20(60.6)$ \\
\hline & AIR MATE & $13(39.4)$ & $20(60.6)$ \\
\hline & Versaflo & $14(42.4)$ & $19(57.6)$ \\
\hline & Koken & $17(51.5)$ & $16(48.5)$ \\
\hline \multirow{4}{*}{$\begin{array}{l}\text { When performing the following tasks (deemed low } \\
\text { risks), do you think a lower flow rate is more } \\
\text { effective? }\end{array}$} & MAX AIR & $11(33.3)$ & $22(66.7)$ \\
\hline & AIR MATE & $15(45.5)$ & $18(54.5)$ \\
\hline & Versaflo & $13(39.4)$ & $20(60.6)$ \\
\hline & Koken & $14(42.4)$ & $19(57.6)$ \\
\hline
\end{tabular}


Table 3.7 PAPR Preference Results

\begin{tabular}{|c|c|c|c|c|}
\hline \multirow[b]{2}{*}{ Question } & \multirow[b]{2}{*}{ Respirator } & \multicolumn{3}{|c|}{$\begin{array}{l}\text { Total number (proportion) } \\
\text { of people preference }\end{array}$} \\
\hline & & Yes $(\%)$ & $x^{2}$ & P-value \\
\hline $\begin{array}{l}\text { When performing the following tasks (deemed low } \\
\text { risks), which type of the following } 5 \text { respirators do you } \\
\text { prefer to use? }\end{array}$ & $\begin{array}{l}\text { MAX AIR } \\
\text { AIR MATE } \\
\text { Versflo } \\
\text { Koken } \\
\text { N95 }\end{array}$ & $\begin{array}{l}10(30.3) \\
8(24.2) \\
6(18.2) \\
5(15.2) \\
4(12.1)\end{array}$ & 3.515 & 0.476 \\
\hline $\begin{array}{l}\text { When performing the following tasks (deemed low } \\
\text { risks), which type of the following } 5 \text { respirators do you } \\
\text { think is more acceptable? }\end{array}$ & $\begin{array}{l}\text { MAX AIR } \\
\text { AIR MATE } \\
\text { Versflo } \\
\text { Koken } \\
\text { N95 } \\
\end{array}$ & $\begin{array}{l}9(27.3) \\
12(36.4) \\
5(15.2) \\
1(3.0) \\
7(21.2) \\
\end{array}$ & 11.091 & $0.026^{*}$ \\
\hline $\begin{array}{l}\text { When performing the following tasks (deemed low } \\
\text { risks), which type of the following } 5 \text { respirators do you } \\
\text { think is more effective? }\end{array}$ & $\begin{array}{l}\text { MAX AIR } \\
\text { AIR MATE } \\
\text { Versflo } \\
\text { Koken } \\
\text { N95 } \\
\end{array}$ & $\begin{array}{l}13(39.4) \\
8(24.2) \\
5(15.2) \\
3(9.1) \\
4(12.1) \\
\end{array}$ & 9.879 & $0.043 *$ \\
\hline $\begin{array}{l}\text { When performing the following tasks (deemed high } \\
\text { risks), which type of the following } 5 \text { respirators do you } \\
\text { prefer to use? }\end{array}$ & $\begin{array}{l}\text { MAX AIR } \\
\text { AIR MATE } \\
\text { Versflo } \\
\text { Koken } \\
\text { N95 }\end{array}$ & $\begin{array}{l}10(30.3) \\
9(27.3) \\
7(21.2) \\
3(9.1) \\
4(12.1)\end{array}$ & 19.131 & $0.001^{*}$ \\
\hline $\begin{array}{l}\text { When performing the following tasks (deemed high } \\
\text { risks), which type of the following } 5 \text { respirators do you } \\
\text { think is more acceptable? }\end{array}$ & $\begin{array}{l}\text { MAX AIR } \\
\text { AIR MATE } \\
\text { Versflo } \\
\text { Koken } \\
\text { N95 }\end{array}$ & $\begin{array}{l}12(36.4) \\
7(21.2) \\
9(27.3) \\
1(3.0) \\
4(12.1)\end{array}$ & 5.636 & 0.228 \\
\hline $\begin{array}{l}\text { When performing the following tasks (deemed high } \\
\text { risks), which type of the following } 5 \text { respirators do you } \\
\text { think is more effective? }\end{array}$ & $\begin{array}{l}\text { MAX AIR } \\
\text { AIR MATE } \\
\text { Versflo } \\
\text { Koken } \\
\text { N95 } \\
\end{array}$ & $\begin{array}{l}11(33.3) \\
7(21.2) \\
8(24.2) \\
4(12.1) \\
3(9.1) \\
\end{array}$ & 11.091 & $0.026^{*}$ \\
\hline
\end{tabular}


Note: * indicates that respirators preference is significantly different at $\alpha=0.05$. Frequency distributions are analyzed by Chi-square goodness of fit, $\alpha=0.05$.

When asked which respirator the subjects preferred to use when conducting low-risk tasks, most subjects chose Max Air (30.3\%), only five subjects chose Koken. When determining which respirator was more acceptable, subjects preferred the Air Mate (36.4\%), followed by Max Air (27.3\%) and versaflo (18.2\%). Koken was the least favorate. In addition, when determining which respirator was most effective, subjects preferred Max Air 39.4\% more than other respirators followed by Air Mate (24.2\%), while 9.1\% subjects Koken.

When deemed as high-risk tasks, Max Air ranked first when determining which respirator the subjects preferred to use (30.3\%), which respirator was more acceptable (36.4\%) and effective (33.3\%). This could be due to the light weight of Max Air. Also, some subjects expressed that the helmet fit more comfortably than others PAPRs. But the subjects who didn't like Max Air because even though the helmet were tight enough, sometimes it still can fall down, and it was also hard for them to move head around, so they did not have so much vision on two sides. Some subjects said that they felt unsafe when wearing Max Air because it's open hood. Koken was the least preferred and acceptable PAPR due to the constantly unstable noise generated by the blower inside the respirators. Some subjects thought that those noise would interfere the communication with patients. Five subjects reported that they smelled some unusual odor when wearing Koken PAPR due to the elastomeric material of Koken. However, subjects thought Koken was more effective than other PAPRs because it is tight fit and right covered the airway. 
There were three subjects felt dizziness and one subject felt nausea when wearing the Versaflo due to the dryness inside the PAPR and bulky backpack battery kit. Even during the data collection, one subject said that she may not be able to complete her duties properly in an emergency situation because she believed that she can't carry that heavier PAPR (4.5 pounds) for more than half an hour. Eye irritation was also reported by two subjects.

\subsubsection{Physiological Results}

The change of cardiopulmonary variables $\left(\mathrm{HR}, \mathrm{RR}, \mathrm{SpO}_{2}\right)$ was shown in Figure 3.2.

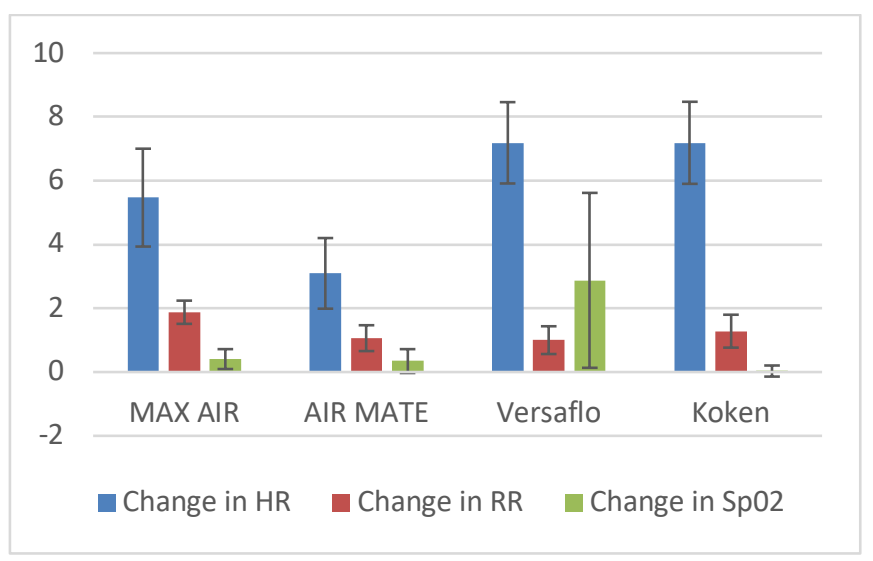

Figure 3.2 Vital Sign Changed Before and After the Test

Table 3.8 Paired t test results of physiological change of HCWs

\begin{tabular}{l|ll}
\hline Respirator & Variable & p-value \\
\hline \multirow{3}{*}{ MAX AIR } & Heart Rate & 0.001 \\
& Respiratory Rate & 0.000 \\
& $\mathrm{SpO}_{2}$ & 0.296 \\
\hline \multirow{4}{*}{ AIR MATE } & Heart Rate & 0.007 \\
& Respiratory Rate & 0.020 \\
& $\mathrm{SpO}_{2}$ & 0.419 \\
\hline \multirow{3}{*}{ Versaflo } & Heart Rate & 0.000 \\
& Respiratory Rate & 0.026 \\
& SpO & 0.310 \\
\hline Koken & Heart Rate & 0.000 \\
\hline
\end{tabular}




\begin{tabular}{l|ll} 
Respiratory Rate & 0.014 \\
$\mathrm{SpO}_{2}$ & 0.860 \\
\hline
\end{tabular}

Out of the three types of vitals taken, the heart rate and respiratory rate were significant changed after taking the test for each PAPR ( $\mathrm{p}<0.05)$. This, however, is most likely due to the experiment design of this study. The measurement of those vital signs was recorded while subject was at rest before starting the test and then, vital signs were measured again after the task of CPR which subjects were in active stage. Because of this, heart rate and respiratory would naturally be higher.

\subsection{Conclusions}

Statistically significant differences were found on categories of general comfort $(\mathrm{p}=0.0009)$, inspiratory/expiratory effort $(\mathrm{p}=0.0001)$, overall breathing discomfort $(\mathrm{p}=0.000)$, difficulty putting on $(\mathrm{p}=0.0092)$ and difficult to operate $(\mathrm{p}=0.0455)$ between four PAPRs. Koken PAPR had the least general comfort, most inspiratory/expiratory effort and overall breathing discomfort followed by Versaflo. Koken did not perform as well as the three traditional PAPRs in most categories except in the category of difficulty to operate and mechanical interference with duties. Max Air was the most preferable respirator in this study for the reason of $\mathrm{HCW}$ being familiar with it and its lightweight and comfortable design.

When conducting low-risk tasks, most of the subjects $(>60 \%)$ thought that the current flow rates of four PAPRs were suitable for them to perform their duties. When asked if a lower flow rate was more acceptable, $42.4 \%$ subjects thought it was more acceptable for a lower flow rate for the Versaflo. And 51.5\% subjects considered a lower flow rate for Koken more accpetable. In addition, when determining whether a lower flow rate was more effective, most of 
subjects thought a lower flow rate would not be more effective for Max Air (66.7\%) and Versaflo (60.6\%). However, nearly $50 \%$ of subjects thought lower flow rates would be more effective for Air mate and Koken.

The physiological variables (HR, RR) significantly changed after the test when wearing PAPRs. The limit of experiment design was the main reason that can explain for it. The perception of facial and body heat and overall thermal discomfort was ameliorated than wearing a N95 in previous study Study II.

\subsection{Limitation}

There are still some limitations in this study. Firstly, when evaluating the preference of a lower flow rate, the subjects only experienced different flow rates. The flow rate of Max Air, Versaflo is constant, whereas the Koken is adjustable. Therefore, it is not consistent when asking whether a lower flow rate is more preferable, acceptable or effective. Secondly, as reported by subjects, communication with patients are so important to them. PAPRs generate noise during the testing. But in the survey, we don't include any questions to evaluate communication interference. Finally, subjects wore the respiorators for only 20-30 minutes, but HCWs usually have to wear the repsirator for several hours.

\subsection{Acknowledgement}

I wish to express my appreciation to Dr. Anna Allen, Dan Summers, Adam Hoffman, Lauren MacDowell, and Brittany Carver for their help, useful suggestions and critique review. This study was supported by the National Institute for Occupational Safety and Health (NIOSH). The contract number is \# 200-2017-M-93679. 


\subsection{Disclaimer}

The findings and conclusions of this article are those of the authors and do not necessarily represent the views of the National Institute for Occupational Safety and Health.

Mention of a commercial product or trade name does not constitute endorsement by the National Institute for Occupational Safety and Health. 


\section{REFERENCES}

1. Robbins Michael. Positve pressure: Powered respirators. OH \& S Canada; Jul/Aug 2002; 18, 5; ProQuest

2. Freund Luanne. Full-featured protection: the journal of industrial health. Occupational Health \& Safety; Nov 2005; 74,11; ProQuest

3. Occupational Safety \& Health Administration. Assigned Protection Factors for the Revised Respiratory Protection Standard. 2009. Available at: https://www.osha.gov/Publications/3352-APFrespirators.html

4. Lenahart S, Campbell D. Assigned protection factors for two respirators types based upon workplace performance testing. The Annals of Occupational Hygiene. 1984 vol: 28 (2) pp: 173-182.

5. daRoza, R.A, C.A. Cadena-Fix, and J.E. Kramer: Powered air purifying respirator study. J. Int. Soc. Respir. Prot. 8(2): 15-36 (1990).

6. Myers, W.R and M.J Peach. Performance measurements on a powered air-purifying respirator made during actual field use in a silica bagging operation. Ann. Occup. Hyg. 27: 251-259 (1983).

7. Myers, W.R, M.J Peach, K. Cutright, and W. Iskander. Workplace protection factor measurements on powered air-purifying respirators at a secondary lead smelter: results and discussion. Ann. Ind. Hyg. Assoc. J. 45: 681-688 (1984).

8. Gaboury A, Burd D, Friar R. Workplace Protection Factor Evaluation of Respiratory Protective Equipment in a Primary Aluminum Smelter. Applied Occupational and Environmental Hygiene

1993. vol: 8 (1) pp: 19-25.

9. Leidel NA, Mullan RJ. NIOSH-Recommended Guidelines for Personal Respiratory Protection of Workers in Health-Care Facilities Potentially Exposed to Tuberculosis. US Department of Health and Human Services, Public H ealth Service, Centers for Disease Control, National I nstitute for Occupational Safety and Health, Atlanta, GA, 1992.

10. $\mathrm{N}$ elson H. USA Objections to protective respirators. L an-cet 1992; $340: 1088$

11. Khoo K, Leng P, Ibrahim I, Lim T. The changing face of healthcare worker perceptions on powered air-purifying respirators during the SARS outbreak. Respirology. 2005 vol: 10 (1) pp: 107-110.

12. J Schumacher, S A Gray, L Weidelt, A Brinker, K Prior, W M Stratling. Comparison of powered and conventional air-purifying respirators during simulated resuscitation of casualties contaminated with hazardous substances. Emergency medicine journal: EMJ2009. vol: 26 (7) pp: 501-5.

13. Arthur T. Johnson, Kathryn R. Mackey, William H. Scott, Frank C. Koh, Ken Y.H. Chiou \& Stephanie J. Phelps. Exercise Performance While Wearing a Tight-Fitting Powered Air Purifying Respirator with Limited Flow. Journal of Occupational and Environmental Hygiene 2005. vol: 2 (7) pp: 368-373.

14. Koken breathing response respirators. Available at: http://www.kokenltd.co.jp/english/product/safe/industrial/fan.html 
15. Xinjian He, Michael Yermakov, Tiina Reponen, Roy T. McKay, Kelley James and Sergey A. Grinshpun. Manikin-Based Performance Evaluation of Elastomeric Respirators Against Combustion Particles. Journal of Occupational and Environmental Hygiene, 2013. 10: 203-212.

16. National Institute for Occupational Safety and Health. NIOSH-Approved Particulate Filtering Facepiece Respirators. Available at:

https://www.cdc.gov/niosh/npptl/topics/respirators/disp_part/default.html

17. Cho, K. J., Jones, S., Jones, G., et al. Effect of Particle Size on Respiratory Protection Provided by Two Types of N95 Respirators Used in Agricultural Settings. (2010) J Occup Environ Hyg 7(11): 622-627.

18. Xinjian He, Evanly Vo, Horvatin M, Liu Y, Bergman M, Zhuang, Z. Comparison of Simulated Workplace Protection Factors Offered by N95 and P100 Filtering Facepiece and Elastomeric Half-Mask Respirators against Particles of 10 to $400 \mathrm{~nm}$. Journal of Nanotechnology and Materials Science. 2015. vol: 2 (2) pp: 1-6

19. CDC. Guidelines for preventing the transmission of Mycobacterium tu-berculosis in health-care settings. December 30, 2005. MMWR Morb Mortal Wkly Rep 2005. Available from: https://www.cdc.gov/mmwr/PDF/rr/rr5417.pdf. Accessed March 15, 2009

20. Occupational Safety and Health Administration. Standard interpretation: tuberculosis and respiratory protection. July 30, 2004.

21. Occupational Safety and Health Administration. Information regarding severe acute respiratory syndrome (SARS). May 30, 2003. Available from: http://www.osha.gov/dep/sars/ . Accessed April 3, 2009.

22. National Institute for Occupational Safety and Health. Understanding respiratory protection against SARS. July 8, 2003. Available from: http://www.cdc.gov/niosh/npptl/t

opics/respirators/factsheets/ respsars.html . Accessed March 22, 2009

23. Rebmann T, Alexander S, Cain T, Citarella B, Cloughessy M, Coll B et al. APIC position paper: Extending the Use and/or Reusing Respiratory Protection in Healthcare Settings During Disaster. 2009.

24. Rebmann T, Wagner W. Infection preventionists' experience during the first month of the 2009 novel H1N1 influenza A pandemic. Am J Infect Control 2009; 37:e5-16.

25. Radonovich LJ, Magalian PD, Hollingfworth MK, Baraco G. Stoclpilling supplies for the next influenza pandemic. Emerg Infect Dis 2009;15:e1.

26. Centers for Disease Control and Prevention. Interim guidance on planning for the use of facemask and respirators in health care settings during an influenza pandemic. 2006. Available from: https://www.cdc.gov/media/pressrel/2007/r070503.htm.

27. Occupational Safety and Health Administration. Pandemic influenza preparedness and response guidance for healthcare workers and healthcare employers. 2007. Available from: https://www.osha.gov/Publications/3328-05-2007-English.html.

28. Goldfrank LR, Liverman CT. Preparing for an influenza pandemic: personal protective equipment for healthcare workers. Washington DC: Institute of Medicine; 2007. 
29. OSHA. Assigned Protection Factors for the Revised Respiratory Protection Standard. 2009. Available from: https://www.osha.gov/Publications/3352-APF-respirators.pdf.

30. Steelnack, J.(2007). Assigned Protection Factor (APF) Table Added to OSHA's Respiratory Protection https://www.aiha.org/aihce07/handouts/rt243steelnack.pdfStandard 29 CFR 1910.134.

31. Baugh, L. (2015). Total Inward Leakage Testing for Respirators. International Safety Equipment Assocaiton. Retrieved from https://safetyequipment.org/knowledge-center-items/total-inwardleakage-testing-for-respirators/

32. Xinjian He, Sergey A. Grinshpun, Tiina Reponen, Roy McKay, Michael S. Bergman, Ziqing Zhuang. 2014. Effects of Breathing Frequency and Flow Rate on the Total Inward Leakage of an Elastomeric Half-Mask Donned on an Advanced Manikin Headform. 2013 . Ann. Occup. Hyg., Vol. 58, No. 2, 182-194.

33. Lee, S., Grinshpun, S.A., \& Reponen, T. (2008). Respiratory Performance Offered by N95 Respirators and Surgical Masks: Human Subject Evaluation with $\mathrm{NaCl}$ Aerosol Representing Bacterial and Viral Particle Size Range, The Annals of Occupational Hygiene, 52(3), 177-185. https://doi.org/10.1093/annhyg/men005

34. Szeinuk J, Beckett WS, Clark N, Hailoo WL. Medical evaluation for respirator use. Am J Ind Med 2000;37(1):142-157. 16.

35. Institute of Medicine. Preparing for an influenza pandemic: personal protective equipment for healthcare workers. Washington, DC: The National Academies Press; 2008.

36. Li, Y, Tokura, H, Guo, Y. P, Wong, A. S W, Wong, T, Chung, J, Newton, E. Effects of wearing N95 and surgical facemasks on heart rate, thermal stress and subjective sensations. 2005. International Archives of Occupational and Environmental Health.

37. Terrell PG. How to increase worker acceptance of respirators. Prof Saf 1984;29:15-20.

38. Bryce E, Forrester L, Scharf S, Eshghpour M. What do healthcare workers think? A survey of facial protection equipment user preferences. J Hosp Infect 2008;68:241-7.

39. Eck EK, Vannier A. The effect of high-efficiency particulate air respirator design on occupational health: a pilot study balancing risks in the real world. Infect Control Hosp Epidemiol 1997; 18:122-7.

40. Akbar-Khanzadeh F, Bisesi MS, Rivas RD. Comfort of personal protective equipment. Appl Ergon 1995;26:195-8.

41. Radonovich LJ, Cheng J, Shenal BV, Hodgson M, Bender BS. Respirator tolerance in health care workers. JAMA 2009;30:36-8.

42. Institute of Medicine. Tuberculosis in the Workplace. Washington, DC: The National Academies Press; 2001.

43. Institute of Medicine. Reusability of facemasks during an influenza pandemic: facing the flu. Washington, DC: The National Academies Press; 2006.

44 Roberge, R., Benson, S., \& Kim, J. (2012). Thermal Burden of N95 Filtering Facepiece Respirators, The Annals of Occupational Hygiene, 56(7), 808-814. 
45. Roberge R, Coca A, Williams J, Powell J, Palmiero A. Physiological impact of the N95 filtering facepiece respirator on healthcare workers. Respiratory Care, May 2010, Vol 55; No 5.

46. Grace Lu-Yu, Peter Albertsen, Weichung Shih, Siu-long Yao. Respirator Tolerance in Health Care Workers. JAMA, Jan 2009, Vol 301.

47. Lim EC, Seet RC, Lee KH, Wilder-Smith EP, Chuah BY, Ong BK. Headaches and the N95 facemask amongst healthcare providers. Acta Neurologica Scandinavica 2006;113:199-202.

48. Baig A, Knapp C, Eagan A, Radonovich L. Health care workers' views about respirator use and features that should be included in the next generation of respirators. American Journal of Infection Control, 2010.

49. Powell, J. B., Kim, J. H., \& Roberge, R. J. (2017). Powered air-purifying respirator use in healthcare: Effects on thermal sensations and comfort. Journal of occupational and environmental hygiene, 14(12), 947-954.

50. Baig A, Knapp C, Eagan A, Radonovich L. (2010). Health care workers' views about respirator use and features that should be included in the next generation of respirators. American Journal of Infection Control.

51. Lenhart, S.W., Seitz, T., Trout, D., \& Bollinger, N. (2004). Issues Affecting Respirator Selection for Workers Exposed to Infectious

52. Roberge, R., S. Benson, and J.-H. Kim: Thermal burden of N95 filtering facepiece respirators. Ann. Occup. Hyg. $56: 808-814$ (2012)

53. Coca, A., T. Quinn, J.-H. Kim, et al: Physiological evaluation of personal protective ensembles recommended for use in West Africa. Dis. Med. Pub. Health Preparedness doi:10.1017/dmp.2017.13 .

54. Food \& Drug Administration. Masks and N95 Respirators. Available at: https://www.fda.gov/medicaldevices/productsandmedicalprocedures/generalhospitaldevicesandsu pplies/personalprotectiveequipment/ucm055977.htm

55. Bałazy A, Toivola M, Adhikari A, Sivasubramani S, Reponen T. Do N95 respirators provide 95\% protection level against airborne viruses, and how adequate are surgical masks? American Journal of Infection Control. (2006) vol: 34 (2) pp: 51-57.

56. OSHA Best Practices for HOSPITAL-BASED FIRST RECEIVERS OF VICTIMS from Mass Casualty Incidents Involving the Release of Hazardous Substances. 2005. Available at: https://www.osha.gov/dts/osta/bestpractices/html/hospital_firstreceivers.html

57. OSHA. Hospital Respiratory Protection Program Toolkit Resources for Respirator Program Administrators. 2015. Available at: https:/www.osha.gov/Publications/OSHA3767.pdf

58. NIOSH-Approved Powered Air-Purified Respirators Meeting CDC Criteria for Ebola. Available at: https://www.cdc.gov/niosh/npptl/topics/respirators/disp_part/paprtables.html

59. Wizner, K., L. Stradtman, D. Novak, and R. Shaffer: Prevalence of respiratory protective devices in U.S. health care facilities. Workplace Health Saf. 64 :359-369 (2016).

60. Fennelly, K.P.: Personal respiratory protection against Mycobacterium tuberculosis. Clin Chest Med. $18: 1-17$ (1997). 
61. Khoo, K.-L., P.-H. Leng, I.B. Ibrahim, and T. Lim: The changing face of healthcare worker perceptions on pow-ered air-purifying respirators during the SARS outbreak. Respirology $10: 107-110$ (2005).

62. Martin, S., Moyer, E., \& Jensen, P. (2006). Integrated Unit Performance Testing of Powered, AirPurifying Particulate Respirators Using a DOP Challenge Aerosol. Journal of Occupational and Environmental Hygiene, 3(11), 631-641. https://doi.org/10.1080/15459620600954365

63. Koivisto, A.J., Aromaa, M., Koponen, I.K., Fransman, W., Jensen, K.A., Makela, J.M., \& Hameri, K.J. (2015). Workplace performance of a loose-fitting powered air purifying respirator during nanoparticle synthesis. Journal of Nanoparticle Research, 17, 177.

64. Gao S, McKay R, Yermakov M, Kim J, Reponen T, He X, Kimura K, Grinshpum S. (2016). Performance of an improperly sized and stretched-out loose-fitting powered air-purifying respirator: Manikin-based study. Journal of Occupational and Environmental Hygiene. vol: 13 (3) pp: 169-176.

65. Cohen, H.J., Hecker, L.H., Mattheis, D.K., Johnson, J.S., Biermann, A.H., \& Foote, K.L. (2001). Simulated Workplace Protection Factor Study of Powered Air-Purifying and Supplied Air Respirators. American Industrial Hygiene Assocation, 62(5), 595-604.

66. Lenhart, S.W., Seitz, T., Trout, D., \& Bollinger, N. (2004). Issues Affecting Respirator Selection for Workers Exposed to Infectious Aerosols: Emphasis on Healthcare Settings. Applied Biosafety, 9(1), 20-36.

67. Zamora, J. E., Murdoch, J., Simchison, B., \& Day, A. G. (2006). Contamination: a comparison of 2 personal protective systems. CMAJ : Canadian Medical Association Journal $=$ Journal de l’Association Medicale Canadienne, 175(3), 249-54. https://doi.org/10.1503/cmaj.060094

68. Crutchfield, C. D., Fairbank, E. O., \& Greenstein, S. L. (1999). Effect of Test Exercises and Mask Donning on Measured Respirator Fit. Applied Occupational and Environmental Hygiene, 14(12), 827-837. https://doi.org/10.1080/104732299302062

69. Evanhoff B, Kim L, Mutha S, Jeffe D, Haase C, Andereck D, et al. Com-pliance with universal precautions among emergency department personnel caring for trauma patients. Ann Emerg Med 1999;33:160-5.

70. Gershon RRM, Vlahov D, Felknow SA, Vesley D, Johnson PC, Delclos GL, et al. Compliance with universal precautions among health care workersatthree regionalhospitals. AmJ InfectControl.1995;23:225-36.

71. Hammond JS, Eckes JM, Gomez GA, Cunningham DN. HIV, trauma, and infection control: universal precautions are universally ignored. J Trauma, 1990;30:555-61.

72. Nickell LA, Crighton EJ, Tracy CS, Al-Enazy H, Bolaji Y, Hanjrah S, et al. Psychosocial effects of SARS on hospital staff: survey of a large tertiary care institution. Can Med Assoc J, 2004;170:793-8.

73. Caretti, D.M., and P.D. Gardner: Quantifying the heat stress attributable to respirator wear. J. Int. Soc. Resp. Protect. 20:110-124 (2003). 


\section{Appendix A: Screening Questionnaire}

\section{Assessing acceptability and perceived protective efficiency of PAPRs}

\section{BASIC INFOMATION}

\begin{tabular}{|c|c|c|c|}
\hline \multirow{2}{*}{\multicolumn{3}{|c|}{$\begin{array}{l}\text { PLEASE PRINT AND CC } \\
\text { NAME OIST }\end{array}$}} & COMPLETE ALL ENTRIES \\
\hline \multicolumn{2}{|c|}{\begin{tabular}{|l|l} 
NAME (LAST -- FIRST -- MIDDLE INITIAL) & -
\end{tabular}} & & JOB TITLE \\
\hline SEX (M or F) & Phone Number & Email Address & YEARS OF WORK EXPERIENCE \\
\hline \multicolumn{2}{|c|}{$\begin{array}{l}\text { Have you used a PAPR before? (Yes o } \\
\text { No) }\end{array}$} & \multicolumn{2}{|c|}{$\begin{array}{l}\text { If you have used a PAPR before, what specific activities do you use it } \\
\text { for? }\end{array}$} \\
\hline \multicolumn{4}{|c|}{ Which hospital unit/department are you from? Please briefly describe your daily work activities. } \\
\hline \multicolumn{4}{|c|}{$\begin{array}{l}\text { What is your experience with the following activities? (1: very experienced, 2: somewhat experienced; 3: } \\
\text { inexperienced) }\end{array}$} \\
\hline \multicolumn{4}{|c|}{\begin{tabular}{l|l} 
Set up bedding/room &
\end{tabular}} \\
\hline \multicolumn{4}{|c|}{ Position patient } \\
\hline \multicolumn{4}{|c|}{ Assess patient } \\
\hline \multicolumn{4}{|c|}{ Hook up monitoring devices } \\
\hline \multicolumn{4}{|c|}{ Insert IV } \\
\hline \multicolumn{4}{|c|}{ Draw blood } \\
\hline \multicolumn{4}{|c|}{ Start IV equipment } \\
\hline \multicolumn{4}{|c|}{ Insert and set up foley } \\
\hline \multicolumn{4}{|c|}{ Take urine sample } \\
\hline \multicolumn{4}{|c|}{ Turn and bathe patient } \\
\hline \multicolumn{4}{|c|}{ Suctioning } \\
\hline & prm CPR & & \\
\hline
\end{tabular}




\section{Appendix B: Survey Questionnaire}

Assessing user discomfort, acceptability and perceived protective efficiency of PAPRs in healthcare work settings

Date:

Study ID:

BASIC INFOMATION
\begin{tabular}{|l|l|l|l|}
\hline PLEASE PRINT AND COMPLETE ALL ENTRIES & JOB TITLE \\
\hline NAME (LAST -- FIRST -- MIDDLE INITIAL) & & \\
\hline SEX & AGE (Years) Weight (Ib.) & Have you used PAPRs? & YEARS OF WORK EXPERIENCE \\
a Male $\quad$ Female & & & \\
& & & \\
\hline
\end{tabular}

List of Tested Respirators:

\begin{tabular}{|l|c|c|c|c|}
\hline \multicolumn{1}{|c|}{ Respirator 1 } & Respirator 2 & Respirator 3 & Respirator 4 & Respirator 5 \\
\hline \multicolumn{1}{|c|}{ Versflow } & Koken & AIR MATE & MAX AIR & N95 \\
\hline $\begin{array}{l}\text { Time } \\
\text { Start: }\end{array}$ & & & & \\
Time & & & & \\
Stop: & & & & \\
\hline
\end{tabular}

Note: The order of all the respirators was completely randomized for each subject test. 


\section{List of Exercises}

Set up bedding/room

Position patient

Assess patient

Hook up monitoring devices

Insert IV

Draw blood

Start IV equipment

Insert and set up foley

Take urine sample

Turn and bathe patient

Suctioning

Perform CPR 
Study ID:

Place a circle next to the following scales corresponding to your evaluation of each respirator.

\begin{tabular}{|c|c|c|c|c|c|c|c|c|c|}
\hline \multicolumn{10}{|c|}{ General comfort } \\
\hline \multicolumn{2}{|c|}{ Respirator 1} & \multicolumn{2}{|c|}{ Respirator 2} & \multicolumn{2}{|c|}{ Respirator 3} & \multicolumn{2}{|c|}{ Respirator 4} & \multicolumn{2}{|c|}{ Respirator 5} \\
\hline $\begin{array}{l}\text { Very poor } \\
1\end{array}$ & $\mathrm{~T}$ & $\begin{array}{l}\text { Very poor } \\
1\end{array}$ & $T$ & $\begin{array}{l}\text { Very poor } \\
1\end{array}$ & $T$ & $\begin{array}{l}\text { Very poor } \\
1\end{array}$ & $T$ & $\begin{array}{l}\text { Very poor } \\
1\end{array}$ & $T$ \\
\hline $\begin{array}{l}\text { Poor } \\
2\end{array}$ & + & $\begin{array}{l}\text { Poor } \\
2\end{array}$ & - & $\begin{array}{l}\text { Poor } \\
2\end{array}$ & $t$ & $\begin{array}{l}\text { Poor } \\
2\end{array}$ & $t$ & $\begin{array}{l}\text { Poor } \\
2\end{array}$ & + \\
\hline $\begin{array}{l}\text { Acceptable } \\
3\end{array}$ & $t$ & $\begin{array}{l}\text { Acceptable } \\
3\end{array}$ & & $\begin{array}{l}\text { Acceptable } \\
3\end{array}$ & 千 & $\begin{array}{l}\text { Acceptable } \\
3\end{array}$ & + & $\begin{array}{l}\text { Acceptable } \\
3\end{array}$ & \\
\hline $\begin{array}{l}\text { Good } \\
4\end{array}$ & t & $\begin{array}{l}\text { Good } \\
4\end{array}$ & $\dagger$ & $\begin{array}{l}\text { Good } \\
4\end{array}$ & $\dagger$ & $\begin{array}{l}\text { Good } \\
4\end{array}$ & $t$ & $\begin{array}{l}\text { Good } \\
4\end{array}$ & $\dagger$ \\
\hline $\begin{array}{l}\text { Very good } \\
5\end{array}$ & - & $\begin{array}{l}\text { Very good } \\
5\end{array}$ & - & $\begin{array}{l}\text { Very good } \\
5\end{array}$ & - & $\begin{array}{l}\text { Very good } \\
5\end{array}$ & - & $\begin{array}{l}\text { Very good } \\
5\end{array}$ & - \\
\hline $\begin{array}{l}\text { Excellent } \\
6\end{array}$ & - & $\begin{array}{l}\text { Excellent } \\
6\end{array}$ & - & $\begin{array}{l}\text { Excellent } \\
6\end{array}$ & - & $\begin{array}{l}\text { Excellent } \\
6\end{array}$ & - & $\begin{array}{l}\text { Excellent } \\
6\end{array}$ & - \\
\hline
\end{tabular}

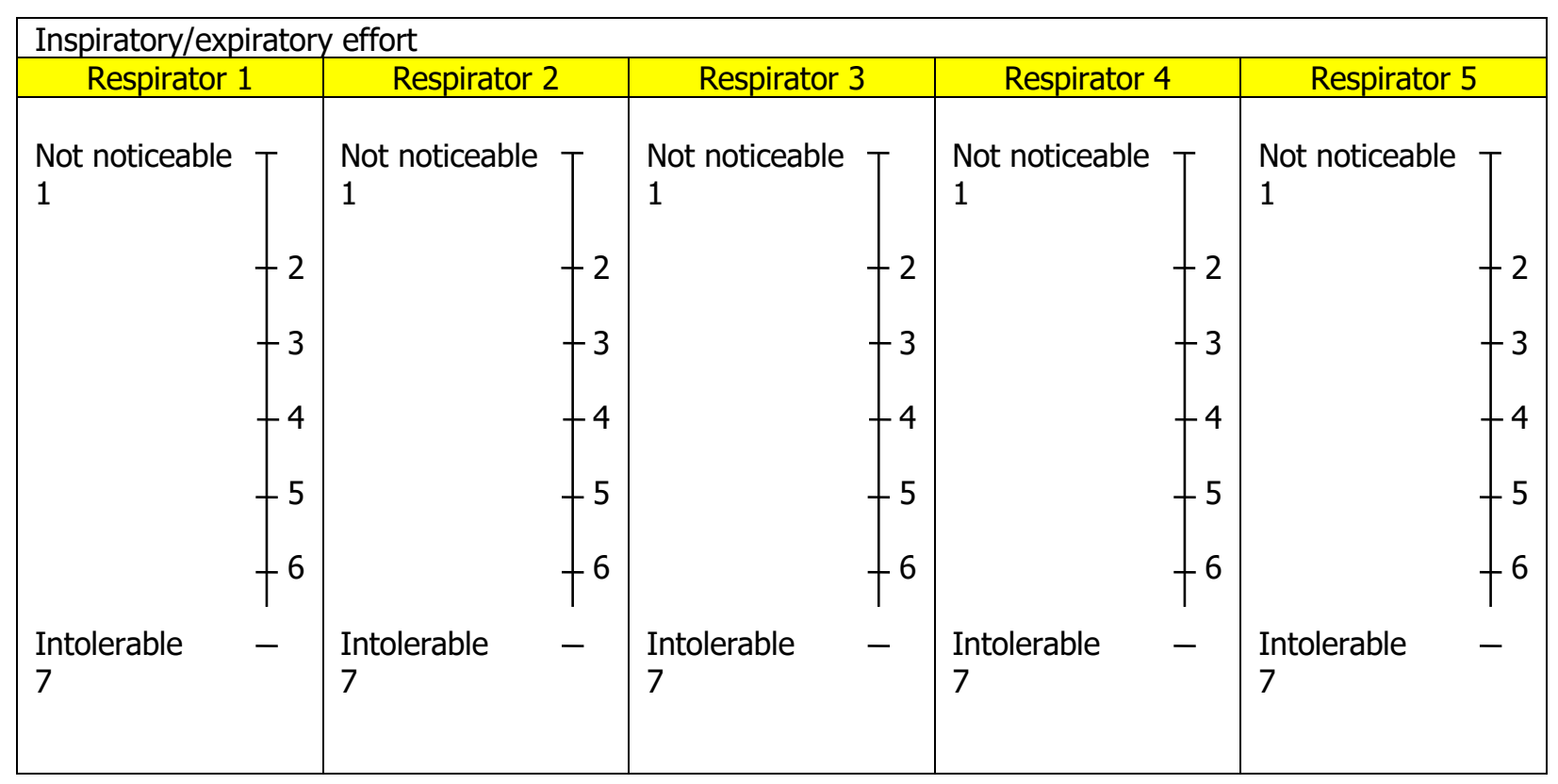


Study ID:

\begin{tabular}{|c|c|c|c|c|c|c|c|c|}
\hline \multicolumn{9}{|c|}{ Overall breathing discomfort } \\
\hline Respirator 1 & \multicolumn{2}{|l|}{ Respirator 2} & \multicolumn{2}{|l|}{ Respirator 3} & \multicolumn{2}{|l|}{ Respirator 4} & \multicolumn{2}{|c|}{ Respirator 5} \\
\hline Not at all & Not at all & $\mathrm{T}^{1}$ & Not at all & $T^{1}$ & Not at all & $\mathrm{T}^{1}$ & Not at all & $T^{1}$ \\
\hline Very slight & Very slight & -2 & Very slight & -2 & Very slight & -2 & Very slight & -2 \\
\hline Slight & Slight & -3 & Slight & -3 & Slight & -3 & Slight & -3 \\
\hline Somewhat high -4 & Somewhat high & -4 & Somewhat high & -4 & Somewhat high & -4 & Somewhat high & -4 \\
\hline $\begin{array}{l}\text { High } \\
5\end{array}$ & $\begin{array}{l}\text { High } \\
5\end{array}$ & $t$ & $\begin{array}{l}\text { High } \\
5\end{array}$ & $\theta$ & $\begin{array}{l}\text { High } \\
5\end{array}$ & $t$ & $\begin{array}{l}\text { High } \\
5\end{array}$ & $t$ \\
\hline Unbearable & Unbearable & -6 & Unbearable & -6 & Unbearable & -6 & Unbearable & -6 \\
\hline
\end{tabular}

\begin{tabular}{|c|c|c|c|c|c|c|}
\hline \multicolumn{7}{|l|}{ Facial and body heat } \\
\hline Respirator 1 & Respirator 2 & Respirator 3 & \multicolumn{2}{|l|}{ Respirator 4} & \multicolumn{2}{|l|}{ Respirator 5} \\
\hline Not at all & Not at all & Not at all & Not at all & $T^{1}$ & Not at all & $T^{1}$ \\
\hline Very slight & Very slight & Very slight & Very slight & -2 & Very slight & -2 \\
\hline Slight & Slight & Slight & Slight & -3 & Slight & -3 \\
\hline Somewhat high -4 & Somewhat high -4 & Somewhat high -4 & Somewhat high & -4 & Somewhat high & -4 \\
\hline $\begin{array}{l}\text { High } \\
5\end{array}$ & $\begin{array}{l}\text { High } \\
5\end{array}$ & $\begin{array}{l}\text { High } \\
5\end{array}$ & $\begin{array}{l}\text { High } \\
5\end{array}$ & $t$ & $\begin{array}{l}\text { High } \\
5\end{array}$ & \\
\hline Unbearable & Unbearable & Unbearable & Unbearable & -6 & Unbearable & -6 \\
\hline
\end{tabular}


Study ID:

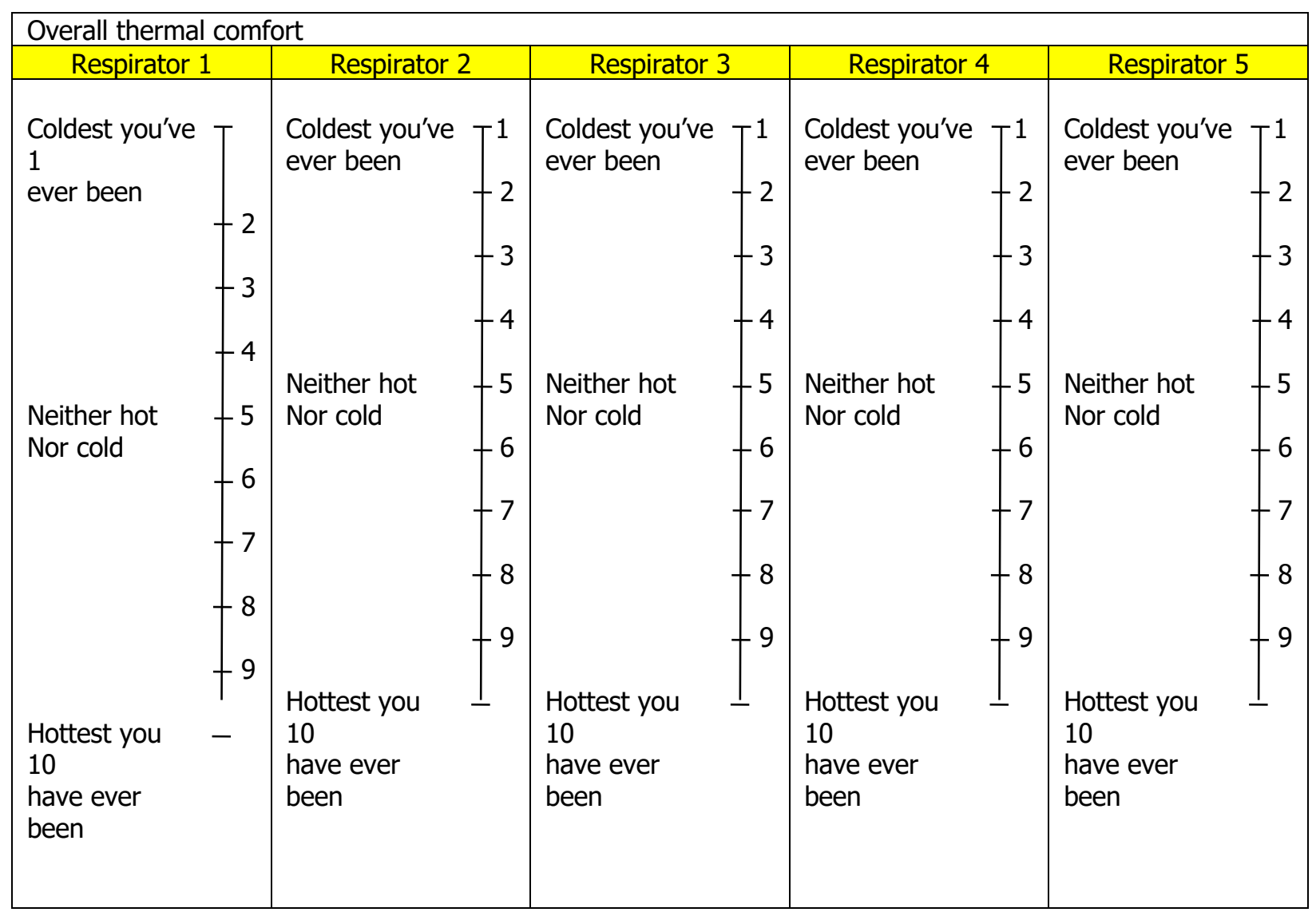

Study ID:

\begin{tabular}{|c|c|c|c|c|c|c|c|c|}
\hline \multicolumn{9}{|l|}{ Pressure or pain } \\
\hline Respirator 1 & \multicolumn{2}{|l|}{ Respirator 2} & \multicolumn{2}{|l|}{ Respirator 3} & \multicolumn{2}{|l|}{ Respirator 4} & \multicolumn{2}{|l|}{ Respirator 5} \\
\hline Not at all & Not at all & $T^{1}$ & Not at all & $T^{1}$ & Not at all & $T^{1}$ & Not at all & $T^{1}$ \\
\hline Very slight & Very slight & -2 & Very slight & +2 & Very slight & -2 & Very slight & -2 \\
\hline Slight & Slight & -3 & Slight & -3 & Slight & -3 & Slight & -3 \\
\hline Somewhat high -4 & Somewhat high & -4 & Somewhat high & -4 & Somewhat high & -4 & Somewhat high & -4 \\
\hline $\begin{array}{l}\text { High } \\
5\end{array}$ & $\begin{array}{l}\text { High } \\
5\end{array}$ & $t$ & $\begin{array}{l}\text { High } \\
5\end{array}$ & $t$ & $\begin{array}{l}\text { High } \\
5\end{array}$ & $t$ & $\begin{array}{l}\text { High } \\
5\end{array}$ & $t$ \\
\hline Unbearable & Unbearable & -6 & Unbearable & -6 & Unbearable & -6 & Unbearable & -6 \\
\hline
\end{tabular}


Study ID:

\begin{tabular}{|c|c|c|c|c|c|c|c|c|}
\hline \multicolumn{9}{|l|}{ Eye discomfort } \\
\hline Respirator 1 & \multicolumn{2}{|l|}{ Respirator 2} & \multicolumn{2}{|l|}{ Respirator 3} & \multicolumn{2}{|l|}{ Respirator 4} & \multicolumn{2}{|l|}{ Respirator 5} \\
\hline Not at all & Not at all & $\mathrm{T} 1$ & Not at all & $\mathrm{T} 1$ & Not at all & $\top 1$ & Not at all & $\mathrm{T} 1$ \\
\hline Very slight & Very slight & -2 & Very slight & -2 & Very slight & -2 & Very slight & -2 \\
\hline Slight & Slight & -3 & Slight & -3 & Slight & -3 & Slight & -3 \\
\hline Somewhat high -4 & Somewhat high & -4 & Somewhat high & -4 & Somewhat high & -4 & Somewhat high & -4 \\
\hline High & High & -5 & High & -5 & High & + & High & 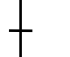 \\
\hline Unbearable & Unbearable & $\perp 6$ & Unbearable & $\perp 6$ & & 1 & & \\
\hline & & & & & Unbearable & -6 & Unbearable & -6 \\
\hline
\end{tabular}

\begin{tabular}{|c|c|c|c|c|c|}
\hline \multicolumn{6}{|c|}{$\begin{array}{l}\text { Interference with wearing glasses/goggles/contact lenses (Don't complete the section if you don't } \\
\text { wear one of those) }\end{array}$} \\
\hline Respirator 1 & Respirator 2 & Respirator 3 & Respirator 4 & Respirator 5 & \\
\hline Not at all & Not at all & Not at all & Not at all & Not at all & $\mathrm{T}^{1}$ \\
\hline Very slight & Very slight & Very slight & Very slight & Very slight & -2 \\
\hline Slight & Slight & Slight & Slight & Slight & -3 \\
\hline Somewhat high -4 & Somewhat high -4 & Somewhat high -4 & Somewhat high -4 & Somewhat high & -4 \\
\hline $\begin{array}{l}\text { High } \\
5\end{array}$ & $\begin{array}{l}\text { High } \\
5\end{array}$ & $\begin{array}{l}\text { High } \\
5\end{array}$ & $\begin{array}{l}\text { High } \\
5\end{array}$ & $\begin{array}{l}\text { High } \\
5\end{array}$ & $t$ \\
\hline Unbearable & Unbearable & Unbearable & Unbearable & Unbearable & -6 \\
\hline
\end{tabular}


Study ID:

\begin{tabular}{|c|c|c|c|c|c|c|c|c|}
\hline \multicolumn{9}{|l|}{ Clear line of vision } \\
\hline Respirator 1 & Respira & & Respira & & Respira & & Respira & \\
\hline $\begin{array}{l}\text { Very poor } \\
1 \\
\text { Poor } \\
2 \\
\text { Acceptable } \\
3 \\
\text { Good } \\
4 \\
\text { Very good } \\
5 \\
\text { Excellent } \\
6\end{array}$ & $\begin{array}{l}\text { Very poor } \\
\text { Poor } \\
2 \\
\text { Acceptable } \\
3 \\
\text { Good } \\
4 \\
\text { Very good } \\
5 \\
\text { Excellent } \\
6\end{array}$ & $\begin{array}{c}T^{1} \\
t \\
- \\
- \\
-\end{array}$ & $\begin{array}{l}\text { Very poor } \\
\text { Poor } \\
\text { Acceptable } \\
3 \\
\text { Good } \\
\text { Very good } \\
5 \\
\text { Excellent }\end{array}$ & $\begin{array}{c}T^{1} \\
-2 \\
-4 \\
-6\end{array}$ & $\begin{array}{l}\text { Very poor } \\
\text { Poor } \\
\text { Acceptable } \\
3 \\
\text { Good } \\
4 \\
\text { Very good } \\
5 \\
\text { Excellent }\end{array}$ & $\begin{array}{c}T^{1} \\
f^{2} \\
t\end{array}$ & $\begin{array}{l}\text { Very poor } \\
\text { Poor } \\
\text { Acceptable } \\
\text { Good } \\
\text { Very good } \\
5 \\
\text { Excellent }\end{array}$ & $\begin{array}{l}T^{1} \\
-3 \\
-4 \\
-6\end{array}$ \\
\hline
\end{tabular}

\begin{tabular}{|c|c|c|c|c|c|c|c|}
\hline \multicolumn{8}{|l|}{ Difficulty of putting on } \\
\hline Respirator 1 & Respirator 2 & \multicolumn{2}{|l|}{ Respirator 3} & \multicolumn{2}{|l|}{ Respirator 4} & \multicolumn{2}{|l|}{ Respirator 5} \\
\hline Not at all & Not at all & Not at all & $T^{1}$ & Not at all & $T^{1}$ & Not at all & $T^{1}$ \\
\hline Very slight & Very slight & Very slight & -2 & Very slight & -2 & Very slight & -2 \\
\hline Slight & Slight & Slight & -3 & Slight & -3 & Slight & -3 \\
\hline Somewhat high -4 & Somewhat high -4 & Somewhat high & -4 & Somewhat high & -4 & Somewhat high & -4 \\
\hline $\begin{array}{l}\text { High } \\
5\end{array}$ & $\begin{array}{l}\text { High } \\
5\end{array}$ & $\begin{array}{l}\text { High } \\
5\end{array}$ & 7 & $\begin{array}{l}\text { High } \\
5\end{array}$ & - & $\begin{array}{l}\text { High } \\
5\end{array}$ & 1 \\
\hline Unbearable & Unbearable & Unbearable & -6 & Unbearable & -6 & Unbearable & -6 \\
\hline
\end{tabular}


Study ID:

\begin{tabular}{|c|c|c|c|c|c|c|}
\hline \multicolumn{7}{|l|}{ Difficulty to operate } \\
\hline Respirator 1 & Respirator 2 & Respirator 3 & \multicolumn{2}{|l|}{ Respirator 4} & \multicolumn{2}{|l|}{ Respirator 5} \\
\hline Not at all & Not at all & Not at all & Not at all & $T^{1}$ & Not at all & $T^{1}$ \\
\hline Very slight & Very slight & Very slight & Very slight & -2 & Very slight & -2 \\
\hline Slight & Slight & Slight & Slight & -3 & Slight & -3 \\
\hline Somewhat high -4 & Somewhat high -4 & Somewhat high -4 & Somewhat high & -4 & Somewhat high & -4 \\
\hline $\begin{array}{l}\text { High } \\
5\end{array}$ & $\begin{array}{l}\text { High } \\
5\end{array}$ & $\begin{array}{l}\text { High } \\
5\end{array}$ & $\begin{array}{l}\text { High } \\
5\end{array}$ & $t$ & $\begin{array}{l}\text { High } \\
5\end{array}$ & + \\
\hline Unbearable & Unbearable & Unbearable & Unbearable & -6 & Unbearable & -6 \\
\hline
\end{tabular}

\begin{tabular}{|c|c|c|c|c|c|c|c|c|}
\hline \multicolumn{9}{|c|}{ Mechanical interference with duties } \\
\hline Respirator 1 & \multicolumn{2}{|l|}{ Respirator 2} & \multicolumn{2}{|l|}{ Respirator 3} & \multicolumn{2}{|l|}{ Respirator 4} & \multicolumn{2}{|l|}{ Respirator 5} \\
\hline Not at all & Not at all & $T^{1}$ & Not at all & $\mathrm{T}^{1}$ & Not at all & $\mathrm{T}^{1}$ & Not at all & $T^{1}$ \\
\hline Very slight & Very slight & -2 & Very slight & -2 & Very slight & -2 & Very slight & -2 \\
\hline Slight & Slight & -3 & Slight & -3 & Slight & -3 & Slight & -3 \\
\hline Somewhat high -4 & Somewhat high & -4 & Somewhat high & -4 & Somewhat high & -4 & Somewhat high & -4 \\
\hline $\begin{array}{l}\text { High } \\
5\end{array}$ & $\begin{array}{l}\text { High } \\
5\end{array}$ & + & $\begin{array}{l}\text { High } \\
5\end{array}$ & $t$ & $\begin{array}{l}\text { High } \\
5\end{array}$ & & $\begin{array}{l}\text { High } \\
5\end{array}$ & + \\
\hline Unbearable & Unbearable & -6 & Unbearable & -6 & Unbearable & -6 & Unbearable & -6 \\
\hline
\end{tabular}


Study ID:

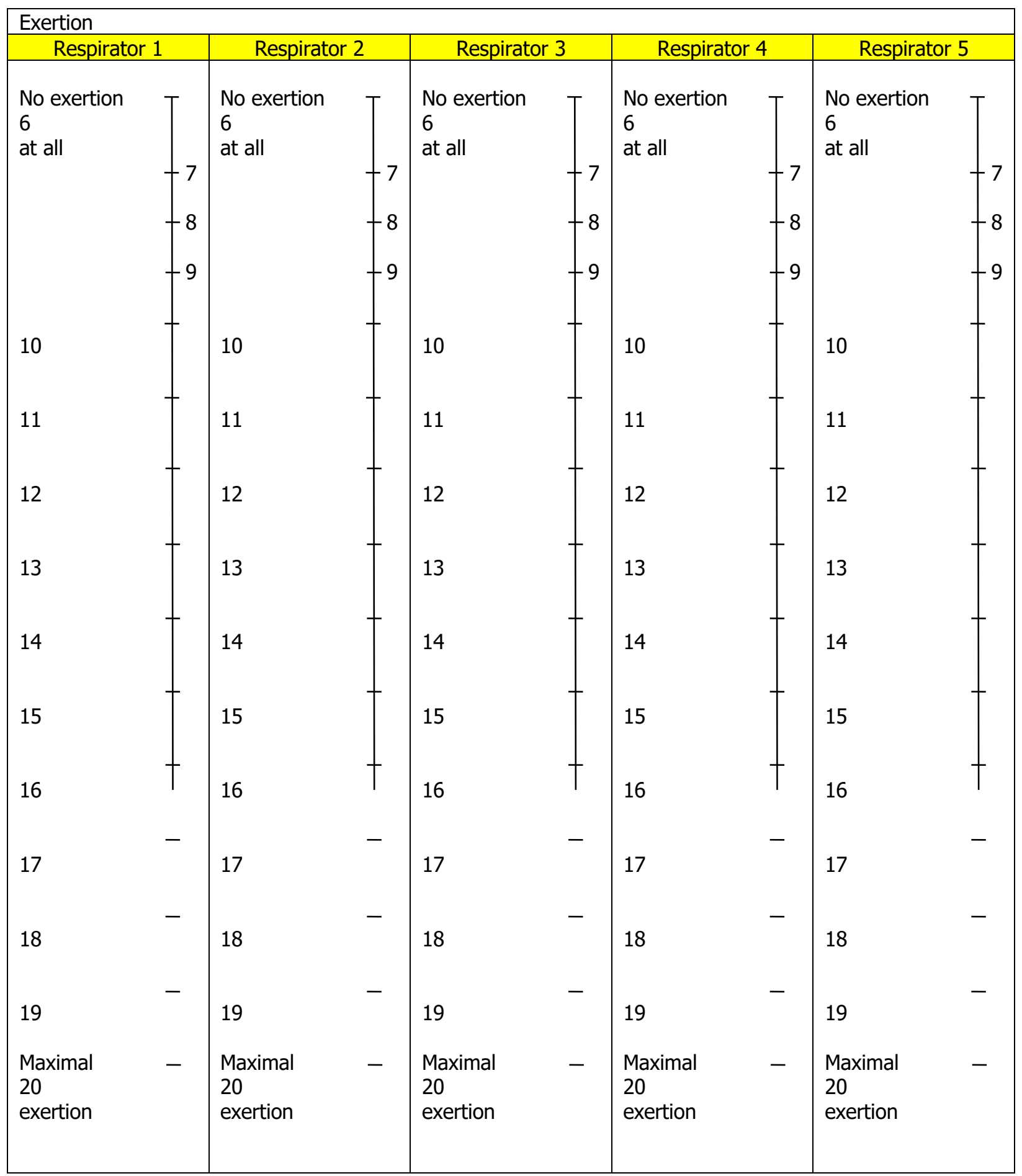


Study ID:

\begin{tabular}{|c|c|c|c|c|}
\hline How many hours do you think you could wear this respirator continuously? \\
\hline Respirator 1 & Respirator 2 & Respirator 3 & Respirator 4 & Respirator 5 \\
\hline & & & & \\
\end{tabular}

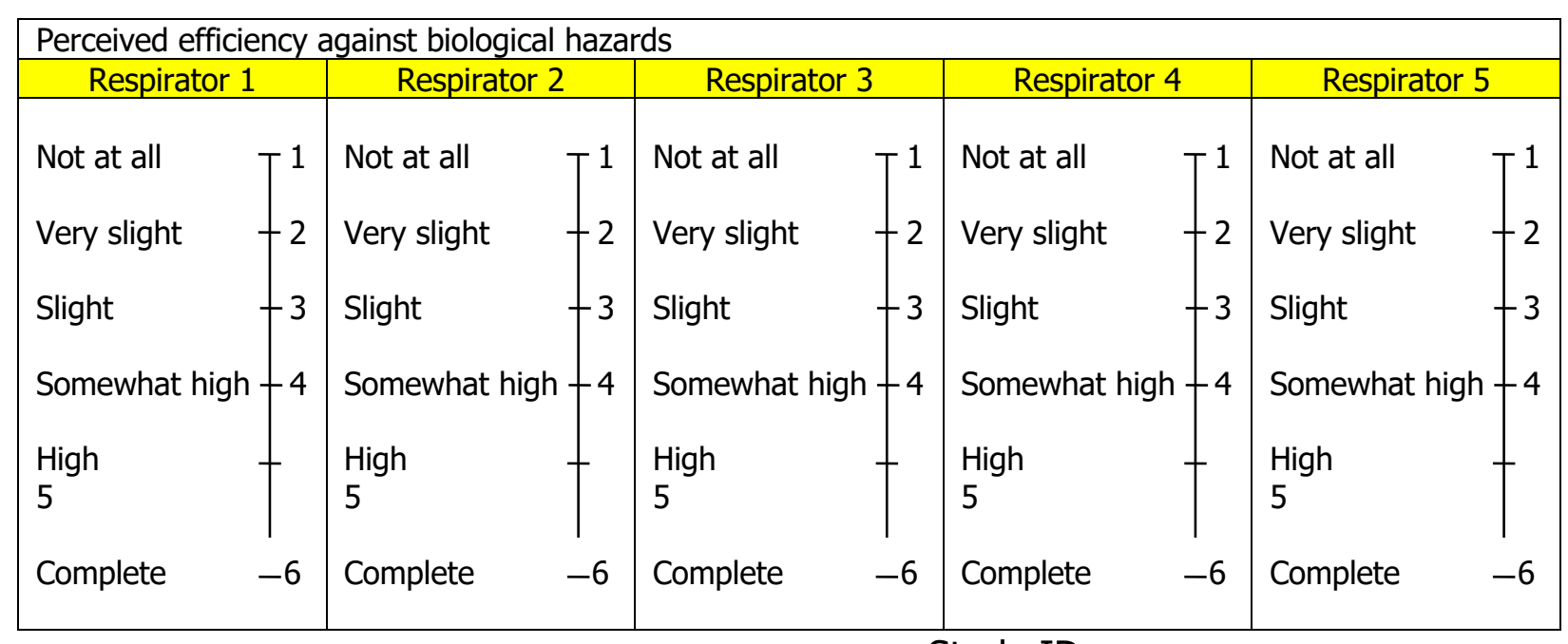

Study ID:

\begin{tabular}{|c|c|c|c|c|c|c|c|c|}
\hline \multicolumn{9}{|l|}{ Overall assessment } \\
\hline Respirator 1 & \multicolumn{2}{|l|}{ Respirator 2} & \multicolumn{2}{|l|}{ Respirator 3} & \multicolumn{2}{|l|}{ Respirator 4} & \multicolumn{2}{|l|}{ Respirator 5} \\
\hline Not at all & Not at all & $T^{1}$ & Not at all & $\mathrm{T}^{1}$ & Not at all & $\mathrm{T}^{1}$ & Not at all & $T^{1}$ \\
\hline Very slight & Very slight & -2 & Very slight & -2 & Very slight & -2 & Very slight & -2 \\
\hline Slight & Slight & -3 & Slight & -3 & Slight & -3 & Slight & -3 \\
\hline Somewhat high -4 & Somewhat high & $h-4$ & Somewhat high & -4 & Somewhat high & -4 & Somewhat high & -4 \\
\hline $\begin{array}{l}\text { High } \\
5\end{array}$ & $\begin{array}{l}\text { High } \\
5\end{array}$ & $t$ & $\begin{array}{l}\text { High } \\
5\end{array}$ & $t$ & $\begin{array}{l}\text { High } \\
5\end{array}$ & $t$ & $\begin{array}{l}\text { High } \\
5\end{array}$ & $t$ \\
\hline Unbearable & Unbearable & -6 & Unbearable & -6 & Unbearable & -6 & Unbearable & -6 \\
\hline
\end{tabular}


Study ID:

\begin{tabular}{|c|c|c|c|c|}
\hline \multirow{2}{*}{$\begin{array}{l}\text { RESPIRATOR } \\
\text { TYPE }\end{array}$} & \multicolumn{3}{|c|}{ VITAL SIGNS } & \multirow{2}{*}{$\begin{array}{c}\text { EXPERIENCE OF USING ANY TYPE OF } \\
\text { RESPIRATOR BEFORE }\end{array}$} \\
\hline & $\begin{array}{l}\text { Heart Rate } \\
\text { (/mins) }\end{array}$ & $\begin{array}{l}\text { Respiratory } \\
\text { Rate(/mins) }\end{array}$ & $\begin{array}{l}\mathrm{SpO2} \\
(\%)\end{array}$ & \\
\hline \multicolumn{5}{|l|}{ Respirator 1} \\
\hline \multicolumn{5}{|l|}{ Respirator 2} \\
\hline \multicolumn{5}{|l|}{ Respirator 3} \\
\hline \multicolumn{5}{|l|}{ Respirator 4} \\
\hline Respirator 5 & & & & \\
\hline
\end{tabular}

AFTER TEST
\begin{tabular}{|l|l|l|l|l|}
\hline \multirow{2}{*}{ RESPIRATOR TYPE } & \multicolumn{3}{|c|}{ VITAL SIGNS } & \multirow{2}{*}{$\begin{array}{c}\text { SPEECH INTELLIGIBILITY TEST } \\
\text { (MRT) }\end{array}$} \\
\cline { 2 - 5 } & $\begin{array}{l}\text { Heart Rate } \\
\text { (/mins) }\end{array}$ & $\begin{array}{l}\text { Respiratory } \\
\text { Rate(/mins) }\end{array}$ & SpO2 (\%) & \\
\hline Respirator 1 & & & & \\
\hline Respirator 2 & & & & \\
\hline Respirator 3 & & & & \\
\hline Respirator 4 & & & & \\
\hline Respirator 5 & & & & \\
\hline
\end{tabular}


Study ID:

QUESTIONNAIRE SURVEY

\begin{tabular}{|c|c|c|c|c|c|}
\hline \multicolumn{6}{|c|}{ Evaluation on preference and acceptability comparing low flow rate with high flow rate for low-risk tasks } \\
\hline Questions & Versflow & Koken & $\begin{array}{c}\text { AIR } \\
\text { MATE }\end{array}$ & $\begin{array}{c}\text { MAX } \\
\text { AIR }\end{array}$ & N95 \\
\hline $\begin{array}{l}\text { When performing the following tasks (deemed low risks), do you prefer a lower } \\
\text { flow rate for the following PAPR? (yes and no for each PAPR model) }\end{array}$ & & & & & N/A \\
\hline $\begin{array}{l}\text { When performing the following tasks (deemed low risks), do you think a lower } \\
\text { flow rate is more acceptable? (yes and no for each PAPR model) }\end{array}$ & & & & & N/A \\
\hline $\begin{array}{l}\text { When performing the following tasks (deemed low risks), do you think a lower } \\
\text { flow rate is more effective? (yes and no for each PAPR model) }\end{array}$ & & & & & $N / A$ \\
\hline
\end{tabular}

\begin{tabular}{|c|c|c|c|c|c|}
\hline \multicolumn{6}{|c|}{ Evaluation on preference and acceptability comparing N95 FFR with evaluated PAPRs for low-risk tasks } \\
\hline Questions & Versflow & Koken & $\begin{array}{c}\text { AIR } \\
\text { MATE }\end{array}$ & $\begin{array}{l}\text { MAX } \\
\text { AIR }\end{array}$ & N95 \\
\hline \multicolumn{6}{|l|}{$\begin{array}{l}\text { When performing the following tasks (deemed low risks), which type of the } \\
\text { following } 5 \text { respirators do you prefer to use? }\end{array}$} \\
\hline \multicolumn{6}{|l|}{$\begin{array}{l}\text { When performing the following tasks (deemed low risks), which type of the } \\
\text { following } 5 \text { respirators do you think is more acceptable? }\end{array}$} \\
\hline $\begin{array}{l}\text { When performing the following tasks (deemed low risks), which type of the } \\
\text { following } 5 \text { respirators do you think is more effective? }\end{array}$ & & & & & \\
\hline
\end{tabular}

\begin{tabular}{|c|c|c|c|c|c|}
\hline \multicolumn{6}{|c|}{ Evaluation on preference and acceptability comparing N95 FFR with evaluated PAPRs for high-risk tasks } \\
\hline Questions & Versflow & Koken & $\begin{array}{c}\text { AIR } \\
\text { MATE }\end{array}$ & $\begin{array}{l}\text { MAX } \\
\text { AIR }\end{array}$ & N95 \\
\hline \multicolumn{6}{|l|}{$\begin{array}{l}\text { When performing the following tasks (deemed high risks), which type of the } \\
\text { following } 5 \text { respirators do you prefer to use? }\end{array}$} \\
\hline \multicolumn{6}{|l|}{$\begin{array}{l}\text { When performing the following tasks (deemed high risks), which type of the } \\
\text { following } 5 \text { respirators do you think is more acceptable? }\end{array}$} \\
\hline $\begin{array}{l}\text { When performing the following tasks (deemed high risks), which type of the } \\
\text { following } 5 \text { respirators do you think is more effective? }\end{array}$ & & & & & \\
\hline
\end{tabular}

Other symptoms

\begin{tabular}{|l|l|l|l|l|l|}
\hline $\begin{array}{l}\text { Somatic complaints for respirators } \\
\text { (Yes and No for each symptom) }\end{array}$ & $\begin{array}{l}\text { Respirator } \\
1\end{array}$ & Respirator 2 & Respirator 3 & $\begin{array}{l}\text { Respirator } \\
4\end{array}$ & $\begin{array}{l}\text { Respirator } \\
5\end{array}$ \\
\hline Nausea & & & & & \\
\hline Dizziness or difficult concentrating & & & & & \\
\hline Unusual smell/odor & & & & & \\
\hline Eye irritation signs (if any) & & & & & \\
\hline
\end{tabular}

\section{List of Tested Respirators:}

\begin{tabular}{|c|c|c|c|c|}
\hline Respirator 1 & Respirator 2 & Respirator 3 & Respirator 4 & Respirator 5 \\
\hline & & & & \\
Versflow & Koken & AIR MATE & MAX AIR & N95 \\
\hline
\end{tabular}


OTHER COMMENTS: 